\title{
Granito Aragão - Suíte intrusiva Nhandú - um granito oxidado, tipo A2, de 1967 a 1964 Ma na Província Aurífera Alta Floresta - Cráton Amazônico Aragão Granite - Nhandú intrusive Suite — an oxidized, A2-type granite, from 1967 to 1964 Ma from the Alta Floresta Gold Province - Amazonian Craton
}

\author{
Samantha Evelyn Max Dezula ${ }^{1,2}$, Marcia Aparecida Sant'Ana Barros ${ }^{1,2}$, Ronaldo Pierosan ${ }^{1,2}$, \\ João Orestes Schneider Santos ${ }^{3}$, Rafael Rodrigues Assis ${ }^{4}$ \\ ${ }^{1}$ Programa de Pós-graduação em Geociências, Faculdade de Geociências, Universidade Federal de Mato Grosso - UFMT, \\ Avenida Fernando Corrêa da Costa, 2.367, CEP 78060-900, Boa Esperança, Cuiabá, MT, BR (samanthadezula@gmail.com; \\ mapabarros@yahoo.com; ronaldo.pierosan@yahoo.com.br) \\ ${ }^{2}$ Grupo de Pesquisa Magmatismo de Mato Grosso - MAGMATO, Faculdade de Geociências, UFMT, Cuiabá, MT, BR \\ ${ }^{3}$ University of Western Australia - UWA, Austrália (orestes.santos@bigpond.com) \\ ${ }^{4}$ Departamento de Petrologia e Metalogenia, Instituto de Geociências e Ciências Exatas, Universidade Estadual Paulista "Júlio \\ de Mesquita Filho" - UNESP, Rio Claro, SP, BR (rafael.assiss@gmail.com)
}

Recebido em 17 de maio de 2016; aceito em 21 de setembro de 2017

\begin{abstract}
Resumo
O Granito Aragão, localizado na Província Aurífera Alta Floresta (PAAF), consiste de um stock granítico de $\sim 80 \mathrm{~km}^{2}$, de granulação média a grossa, textura porfirítica e composição modal monzogranítica a sienogranítica. Os dados geoquímicos indicam afinidade com magmas graníticos tipo-A2, similares àqueles gerados em margens continentais ativas evoluídas. As idades de cristalização U-Pb SHRIMP em zircão de $1964 \pm 11$ Ma e $1967 \pm 2$ Ma permitem incluí-lo na Suíte Intrusiva Nhandú (SINH) e correlacioná-lo com a Suíte Intrusiva Creporizão (SIC) na Província Mineral do Tapajós (PMT), no Pará. Associado ao Granito Aragão ocorre um megaenclave fanerítico médio a grosso, de textura porfirítica e composição modal granodiorítica a monzogranítica. O enclave apresenta padrão geoquímico semelhante a magmas graníticos shoshoníticos, e sua idade de cristalização U-Pb SHRIMP em zircão (1995 \pm 5 Ma) indica relação com granitoides do Complexo Cuiú-Cuiú. O Granito Aragão ocorre alojado em granitoides foliados com idade de cristalização U-Pb SHRIMP de $2009 \pm 4$ Ma. Estes resultados sugerem que as rochas hospedeiras do Granito Aragão fazem parte do Complexo Cuiú-Cuiú. As correlações estratigráficas estabelecidas no presente trabalho indicam que a porção leste da PAAF representa a extensão da Província Tapajós-Parima, ao sul do Gráben do Cachimbo, norte do Estado de Mato Grosso.
\end{abstract}

Palavras-chave: Suíte Intrusiva Nhandú; Geoquímica; Cráton Amazônico; Geocronologia U-Pb.

\begin{abstract}
The Aragão Granite, located at the Alta Floresta Gold Province (AFGP), consists of a granitic stock of around $80 \mathrm{~km}^{2}$ with medium to thick granulation, porphyritic texture and monzogranitic to sienogranitic modal composition. Geochemical data indicate to an A2-type affinity, similar to granitic magmas of evolved active continental margins. The U-Pb SHRIMP in zircon crystallization ages of $1964 \pm 11 \mathrm{Ma}$ and $1967 \pm 2$ Ma allow its inclusion into the Nhandú Intrusive Suite and its correlation with the Creporizão Intrusive Suite of the Tapajós Mineral Province (TMP), in the Pará State. Associated with Aragon granite, a porphyrithic megaenclave medium to thick, with porphyritic texture and granodioritic to monzogranitic modal composition, occurs. The enclave presents a geochemical pattern similar to shoshonitic granitic magmas, and their crystallization age U-Pb SHRIMP in zircon (1995 $\pm 5 \mathrm{Ma})$ indicates relation with granitoids of the Cuiú-Cuiú Complex. The Aragão Granite occurs hosted in a foliated granites where the U-Pb SHRIMP crystallization age is $2009 \pm 4 \mathrm{Ma}$. These results suggest that the host rocks of Aragao Granite are part of the Cuiú-Cuiú Complex. The stratigraphical correlation determined in this work indicates that the eastern portion of AFGP represents the extension of Tapajós-Parima Province, south of Cachimbo Graben, north of Mato Grosso State.
\end{abstract}

Keywords: Nhandú Intrusive Suite; Geochemistry; Amazon Craton; U-Pb Geochronology. 


\section{INTRODUÇÃO}

A sistemática de classificação de granitoides, tanto em seus aspectos mineralógicos quanto geoquímicos, tem sido objeto de amplo debate no último século e permanece uma questão controversa, conforme demonstrado por diversos autores - Bowden et al. (1984), Cobbing (1996), Barbarin (1999), Frost et al. (2001), Sheth et al. (2002), Arculus (2003), Chappell (2004) e Nardi (2016). As principais discussões referentes à gênese de magmas graníticos estão centradas em sua origem (e.g. crustal, mantélica ou mista), assim como em seus ambientes geotectônicos de formação.

A origem mantélica, ou seja, a geração de magmas graníticos a partir da cristalização fracionada de magmas básicos, está intimamente vinculada aos conceitos de séries magmáticas de Lameyre e Bowden (1982). Os principais fundamentos referentes à nomenclatura das séries graníticas, propostos por esses autores, são estabelecidos por critérios petrográficos e tendências de diferenciação no diagrama Streckeisen. As afinidades e os critérios geoquímicos utilizados na nomenclatura de séries magmáticas estão fundamentados nos índices de Peacock (1931), que definem tendências, desde rochas básicas até ácidas, que permitem a determinação das mesmas. Destaca-se que o termo "cálcio-alcalino", amplamente difundido na literatura, tem relação direta e restrita com as séries magmáticas de diferenciação. Por outro lado, a nomenclatura de granitos gerados por anatexia, os granitos de fusão crustal, é estabelecida principalmente com base em critérios geoquímicos, conforme estabelece a classificação alfabética de granitos de Chappell e White (1984) e de Whalen et al. (1987). É importante salientar que os granitos tipo-I possuem assinaturas geoquímicas similares às de granitos de séries cálcio-alcalinas.

A determinação do ambiente geotectônico no qual um magma granítico teria se formado é facilmente estabelecida quando os granitos são de origem mantélica. Pode-se usar como exemplo os granitos de arcos magmáticos, que apresentam um padrão geoquímico mais evoluído à medida que o arco magmático se torna mais maduro. Com base nessa premissa, Pearce et al. (1984) elaboraram os diagramas de classificação geotectônica de granitos, amplamente mencionados na literatura mundial. No entanto, a classificação geotectônica de granitos de fusão crustal, com base em seus padrões geoquímicos de elementos-traço, é de acuracidade questionável, uma vez que tais padrões são extremamente dependentes da fonte progenitora do magma e do processo de cristalização fracionada, e não do ambiente geotectônico no qual o magma teria sido gerado.

Nesse contexto, constata-se a dificuldade na determinação da afinidade geoquímica e do ambiente geotectônico de granitoides, quando na ausência de termos composicionais intermediários a básicos Nardi (2016). Assim, verifica-se que o contexto geológico e geotectônico regional de determinado corpo granítico é fundamental para a compreensão da gênese do granitoide em questão.

A Província de Alta Floresta (PAAF), localizada na porção centro-sul do Cráton Amazônico (norte do Estado de Mato Grosso), é constituída por sequências pluto-vulcânicas paleoproterozoicas derivadas de sucessivos eventos orogenéticos que geraram granitoides cálcio-alcalinos a alcalinos com correspondentes supracrustais. A província se enquadra entre as províncias geocronológicas VentuariTapajós (1,9-1,8 Ga) e Rio Negro-Juruena (1,8 - 1,55 Ga), segundo Tassinari e Macambira (1999), ou entre as províncias tectônicas de Tapajós-Parima $(2,1-1,87 \mathrm{Ga})$ e Rondônia-Juruena (1,82 - 1,54 Ga), no modelo de Santos et al. (2000). Essas diferenças acarretam dificuldades para definir de forma mais acurada os limites entre as províncias e, consequentemente, a evolução da PAAF. No modelo de Tassinari e Macambira (1999), por exemplo, o limite inferior da Província Geotectônica Ventuari-Tapajós $(1,95-1,8$ $\mathrm{Ga}$ ) não suporta idades mais antigas do que $1,95 \mathrm{Ga}$, contrariando os dados que veem sendo obtidos na região entre 1,98 a 2,1 Ga e apresentados neste trabalho.

Dessa forma, considera-se neste trabalho que a área esta inseria na Provincia Tectonica Tapajós Parima ( PTTP) de Santos et al., (2000). A PTTP corresponde a um dos maiores e mais bem preservados orógenos orosirianos do mundo. No Brasil, ele se estende por cerca de $2.000 \mathrm{~km}$ no Cráton Amazônico, ainda que muitas vezes esteja afetado por processos estaterianos derivados do desenvolvimento e da amalgamação das províncias vizinhas (Rio Negro e Rondônia-Juruena: Santos et al., 2004). Nesse segmento geológico ocorrem diversos depósitos auríferos disseminados em plútons graníticos oxidados, de médio a alto K, cálcio-alcalinos, peraluminosos a metaluminosos, magnesianos a ferroso, com idades entre 1965 e $1992 \mathrm{Ma}$. Os granitos Novo Mundo e Santa Helena (Paes de Barros, 2007), assim como a Suíte Intrusiva Pé Quente (Assis, 2011), são exemplos de unidades de $\sim 1,98$ Ga que hospedam importantes mineralizações auríferas na província, como os depósitos Luizão, Edú e Pé Quente. Além disso, extensiva atividade garimpeira tem se desenvolvido no entorno dos granitos Nhandú ( 1,96 Ga) e Aragão (1,93 Ga). No conjunto, essas unidades graníticas são agrupadas na Suíte Intrusiva Nhandú (SINH), correlacionável à Suíte Intrusiva Creporizão (SIC), no Pará, geradas durante a construção do arco Creporizão (Santos et al., 2004).

A noroeste da PAAF, o Granito Aragão ocorre em área extensivamente lavrada por garimpeiros, associado a zonas fortemente hidrotermalizadas com ocorrências de zonas sulfetadas sobre o maciço.

O objetivo deste trabalho é caracterizar o Granito Aragão com base em dados petrográficos, geoquímicos e geocronológicos do Granito Aragão e de suas encaixantes. Comparações com outras suítes graníticas de região são feitos com os dados 
disponíveis na literatura. São abordadas questões relativas à classificação, à ambiência tectônica, às fontes magmáticas e aos processos de diferenciação dos granitoides.

\section{MATERIAIS E MÉTODOS}

O procedimento inicial consistiu na descrição petrográfica de 11 amostras em microscópio petrográfico convencional. A descrição deu suporte para o posterior envio das amostras para as análises geoquímicas de rocha total. A determinação de elementos maiores, menores e traço foi efetuada pelo Acme Analytical Laboratories Ltd., em Vancouver, Canadá. Os elementos maiores foram determinados por Inductively Coupled Plasma - Emission Spectrometry (ICP-ES), enquanto os elementos-traço, incluindo os elementos terras raras, por Inductively Coupled Plasma-Mass Spectrometry (ICP-MS).

Datações U-Pb SHRIMP foram efetuadas em cristais de zircão provenientes de quatro amostras do Granito Aragão, as quais foram britadas e pulverizadas. A concentração mineral ocorreu por meio de bateamento, separador magnético, líquidos densos e, finalmente, catação manual sob lupa binocular. Previamente às datações, os zircões foram montados em resina epóxi e imageados com o auxílio do Microscópio Eletrônico de Varredura Tescan-VEGA3 (UWA). Os dados isotópicos foram obtidos por microssonda iônica SHRIMP II no Laboratório de Geocronologia da Curtin University, em Perth, Austrália. A metodologia seguiu os parâmetros descritos por Williams (1998), e as correções de chumbo comum foram feitas utilizando-se contagens de ${ }^{204} \mathrm{~Pb}$. O padrão internacional usado para a calibração das relações $\mathrm{Pb} / \mathrm{U}$ e dos teores de U foi o BR-266, cuja idade ${ }^{206} \mathrm{~Pb} /{ }^{238} \mathrm{U}$ é de $559 \mathrm{Ma}$ e o conteúdo de $\mathrm{U}$, de 903 ppm. O cálculo das idades foi realizado por meio do software Isoplot/EX de Ludwig (2001). Diagramas concórdia foram elaborados com $2 \sigma$ e intervalo de confiança de $95 \%$ (IC95\%).

\section{CONTEXTO GEOLÓGICO GEOTECTÔNICO}

A Província Aurífera Alta Floresta (PAAF) consiste de uma área alongada na direção NW-SE, limitada ao sul pelo gráben dos Caiabis e ao norte pelo gráben do Cachimbo, que a separa da Província Mineral do Tapajós (PMT), no Pará. Duas propostas de compartimentação do Cráton estão atualmente vigentes, de modo que a localização da PAAF difere a depender do modelo adotado. Nesse sentido, a província se insere entre as províncias geocronológicas de Ventuari-Tapajós (1,95 - 1,8 Ga) e Rio Negro-Juruena (1,8 - 1,55 Ga) (Tassinari e Macambira, 1999) ou, então, entre as províncias tectônicas Tapajós-Parima (2,03 - 1,88 Ga) e Rondônia-Juruena (1,82 1,54 Ga) (Santos et al., 2000).
Entretanto, independentemente da compartimentação adotada, dados geológicos, estratigráficos, geoquímicos e isotópicos sugerem que as unidades pluto-vulcânicas que compõem tais províncias se originaram a partir de um modelo mobilístico (mobile belts), com o desenvolvimento de arcos magmáticos que se agregaram progressivamente ao protocráton paleoproterozoico designado Província Amazônia Central (Tassinari e Macambira, 1999; Souza et al., 2005; Santos, 2006; Silva e Abram, 2008). Esses arcos magmáticos teriam evoluído tanto por processos de diferenciação mantélica quanto por processos acrescionário e de retrabalhamento de crosta continental.

De modo geral, a PAAF é constituída por sequências pluto-vulcânicas paleoproterozoicas que exibem idades de cristalização de 1,75 a 2,03 Ga, idades modelo $\mathrm{Nd}$ (TDM) entre 2,76 e 2,15 Ga, além de valores $\mathrm{e}_{\mathrm{Nd}(\mathrm{t})}$ entre -7,62 e 3,09 (Moura, 1998; Santos et al., 2000; Souza et al., 2005; Paes de Barros, 2007; Silva e Abram, 2008; Assis et al., 2014; Assis, 2015; Bettencourt et al., 2016). Esses dados são coerentes com os demais domínios acrescionários do Cráton, visto que indicam magmatismo de fonte arqueana a dominantemente paleoproterozoica, em ambiente de arco juvenil, porém, com variada contribuição crustal. De acordo com Assis (2015), as unidades que compõem a província podem ser agrupadas em quatro domínios geológicos principais:

- embasamento granítico deformado e metamorfizado $(2,81-1,99 \mathrm{Ga})$;

- sequências plutono-vulcânicas e vulcanossedimentares félsicas pertencentes à série da magnetita (granitos tipo I; 1,97 - $178 \mathrm{Ga})$;

- unidades plutono-vucânicas pós-orogênicas e anorogênicas $(1,78-1,77 \mathrm{Ga})$;

- $\quad$ sequências sedimentares clásticas ( 1,37 Ga).

Na PAAF, o embasamento é constituído por gnaisse com idades de protólito entre 2,79 e 2,84 Ga e denominado Gnaisse Gavião (Paes de Barros, 2007; Santos et al., 2015). Gnaisses graníticos a tonalíticos e migmatitos com idades de protólito de 1,99 a 1,90 Ga (Souza et al., 2005; Paes de Barros, 2007; Assis, 2015) são agrupados no Complexo Cuiú-Cuiú, por apresentarem características similares a esse complexo na PMT.

O Complexo Cuiú-Cuiú é intrudido por diversos granitoides cálcio-alcalinos oxidados, pertencentes às sequências plutono-vulcânicas e vulcanossedimentares félsicas. Incluídos nesse grupo estão a Suíte Pé Quente (1,97 Ga; Assis, 2011; Miguel Júnior, 2011), granitos Novo Mundo (1,97 - 1,96 Ga; Paes de Barros, 2007), Aragão (1,93 Ga; Miguel Júnior, 2011) e Flor da Mata, de idade indeterminada. Essas unidades não estão deformadas e/ou metamorfizadas, e correspondem aos sistemas graníticos mais antigos do segmento leste da província. Com exceção do Granito Flor da Mata, os demais hospedam mineralizações auríferas filonares ou disseminadas. Essas rochas ainda são truncadas 


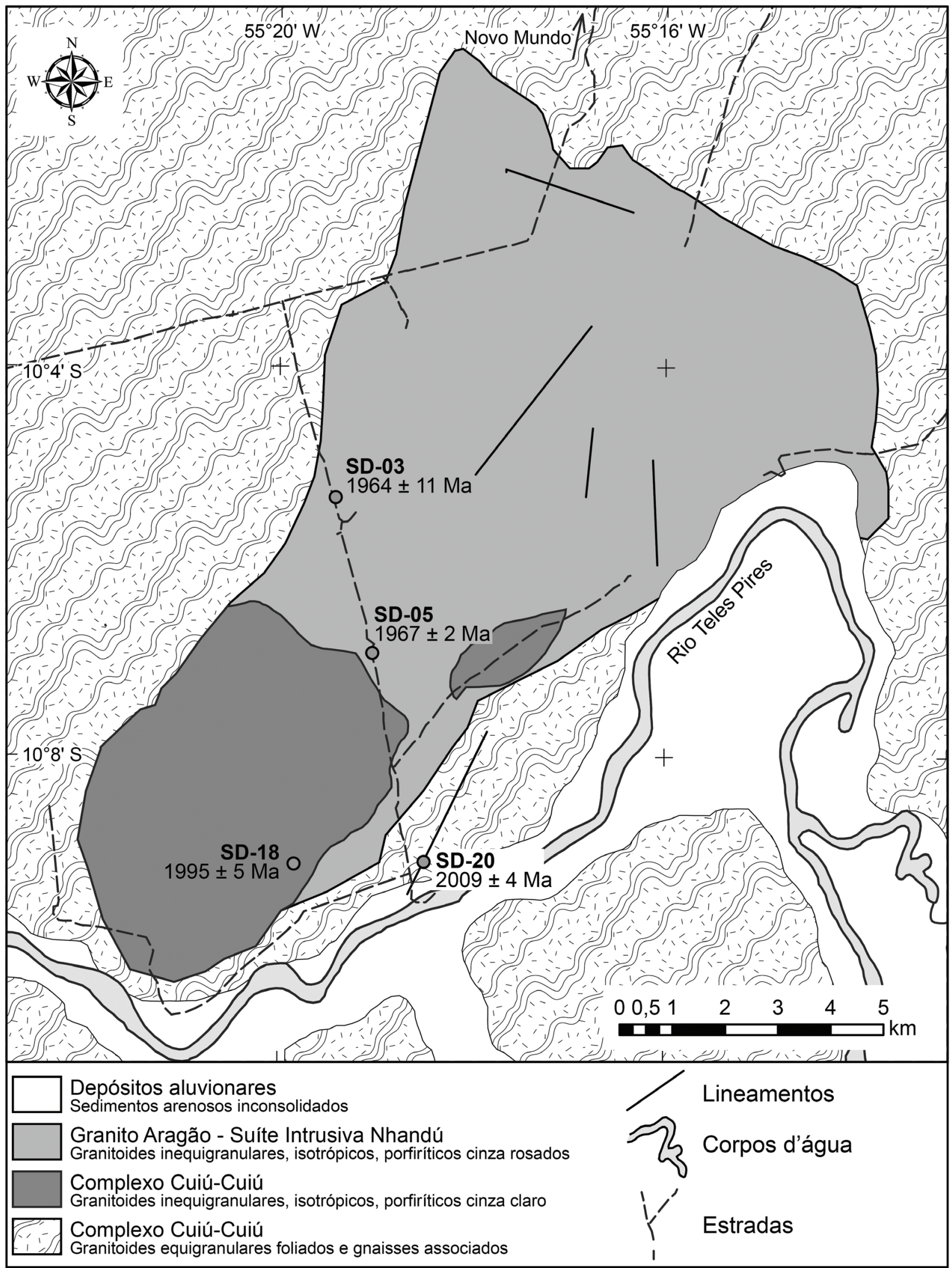

Figura 1. Mapa geológico da área de estudo, na área de ocorrência do Granito Aragão com a localização das amostras datadas. 
pelas Suítes Intrusivas Nhandú (1,97-1,96 Ga: Barros et al., 2015), Matupá (1,87 - 1,86 Ga: Moura, 1998; Souza et al., 2005; Assis, 2015), Juruena (1,82 - 1,85 Ga: JICA/MMAJ, 2000; Silva e Abram, 2008) e Granito Peixoto (1,78 - 1,79 Ga; Paes de Barros, 2007; Silva et al., 2014).

Intrusivas ou na forma de extensos derrames félsicos sobre as rochas citadas, ocorrem as unidades pluto-vulcânicas pós-orogênicas a anorogênicas, essencialmente representadas pelo Grupo Colíder (ca. 1,78 Ga) e pela Suíte Intrusiva Teles Pires - SITP (1,78 - 1,75 Ga) (Moreton e Martins, 2005; Souza et al., 2005; Silva e Abram, 2008; Assis, 2015).

No conjunto, todas essas unidades estão recobertas pelas rochas sedimentares clásticas arenosas do Grupo Beneficente e da Formação Dardanelos. As idades $\mathrm{Pb}-\mathrm{Pb}$ em cristais de zircão detrítico da Formação Dardanelos estão compreendidas entre $1987 \pm 4 \mathrm{Ma}$ e $1377 \pm 13 \mathrm{Ma}$, enquanto as rochas do Grupo Beneficente apresentam idades $\mathrm{Pb}-\mathrm{Pb}$ entre 2,6 e 1,72 Ga (Leite e Saes, 2003). Esses dados sugerem que o Grupo Beneficente iniciou a sua deposição em torno de 1720 Ma, sendo mais antigo em relação à Formação Dardanelos, que mostra idade máxima de deposição de 1,37 Ga. É importante ressaltar que as idades encontradas nos detritos de ambas as bacias (2646 Ma, $1960 \mathrm{Ma}, 1920$ Ma, $1987 \mathrm{Ma}, 1887 \mathrm{Ma}, 1720 \mathrm{Ma}$ e $1377 \mathrm{Ma}$ ) mostram intervalos coerentes com as rochas das províncias Amazônia Central, Tapajós-Parima e Rondônia-Juruena.

\section{ARCABOUÇO GEOLÓGICO}

O corpo granítico que constitui o Granito Aragão foi inicialmente individualizado por Paes de Barros (2007), que o relaciona à Suíte Intrusiva Teles Pires. Vitório (2010), com base em estudos petrográficos e geoquímicos, define o Granito Aragão como um batólito alongado de direção NE-SW, com aproximadamente $115 \mathrm{~km}^{2}$, aflorando na porção sul do município de Novo Mundo. Esse autor divide o Granito Aragão em duas fácies petrográficas:

- granítica porfirítica a fanerítica média;

- microgranítica.

Os dados geoquímicos apresentados por Vitório (2010) apontam para uma afinidade com granitos tipo-A2, o que levou o autor a correlacionar o Granito Aragão com a Suíte Intrusiva Teles Pires, ressaltando a importância da obtenção de dados geocronológicos.

Os estudos de campo e petrográficos realizados permitiram reconhecer granitoides isotrópicos associados à área delimitada para o Granito Aragão (Figura 1), divididos em duas fácies petrográficas inequigranulares média a grossa, porfiríticas, que se distinguem macroscopicamente pela cor e pelo conteúdo de minerais máficos. A fácies cinza rosada possui em torno de $5 \%$ de minerais máficos, ocupa uma área de $80 \mathrm{~km}^{2}$, nas porções central e nordeste do corpo, e tem composições monzograníticas a sienograníticas. A fácies cinza-clara possui minerais máficos entre 10 e $15 \%$, ocorre na porção sudoeste, com extensão de $\sim 30 \mathrm{~km}^{2}$, e tem composições granodioríticas a monzograníticas. O contato entre esses dois litotipos é difuso e transicional, sugerindo a atuação de processos de reabsorção magmática. Os modos de ocorrência de ambas as fácies são representados por lajedos in situ, matacões e blocos, geralmente compondo elevações. Injeções aplíticas, pegmatíticas e veios de quartzo são frequentes, enquanto enclaves máficos ocorrem de forma subordinada.

Na porção sudeste do corpo, trabalhos de reconhecimento regional identificaram biotita granitoides foliados, com foliação penetrativa típica de granitoides sin-orogênicos, previamente agrupados por Paes de Barros (2007) e Assis (2015) sob a denominação informal de Granitoides do Embasamento. Contatos litológicos entre esses dois granitoides não foram observados em campo. As feições petrográficas permitiram agrupá-los em uma fácies equigranular média foliada.

Novos dados geoquímicos e geocronológicos aqui apresentados permitem relacionar a fácies cinza rosada com a SINH, sendo esta fácies, devido ao seu caráter dominante, interpretada como representativa do Granito Aragão. A fácies cinza-clara, por sua vez, foi correlacionada com o Complexo Cuiú-Cuiú, da PMT, de modo semelhante à fácies equigranular média foliada, que pode ser interpretada como encaixante do Granito Aragão.

\section{Fácies inequigranular cinza rosada: Granito Aragão - Suíte Intrusiva Nhandú}

Os granitoides dessa fácies consistem em rochas de cor cinza rosada, faneríticas inequigranulares média a grossa e com conteúdo de minerais máficos em torno de 5\% (Figura 2A). Exibem textura hipidiomórfica a xenomórfica, com conteúdo modal em torno de $45 \%$ de feldspato alcalino, $25 \%$ de plagioclásio, $25 \%$ de quartzo, $3 \%$ de biotita e $2 \%$ de hornblenda. Os minerais acessórios são compostos de zircão, magnetita e titanita.

O feldspato alcalino é subédrico a anédrico, possui frequentes lamelas de pertita em flames e gotículas, além de inclusões subédricas de plagioclásio. Feldspatos alcalinos com macla tartan ocorrem de forma subordinada e exibem dimensões de 2,5 a 10,0 mm (Figura 2B). O plagioclásio ocorre dominantemente como cristais subédricos, com macla polissintética característica e dimensões em torno de 1,5 a $4,5 \mathrm{~mm}$. Os cristais de quartzo são essencialmente anédricos, com extinção ondulante fraca e raramente desenvolvem subgrãos, devido a processos localizados de deformação no estado sólido. As dimensões do quartzo variam de 2,5 a $5,0 \mathrm{~mm}$. Os minerais máficos, biotita e hornblenda, ocorrem como cristais anédricos a subédricos parcialmente 

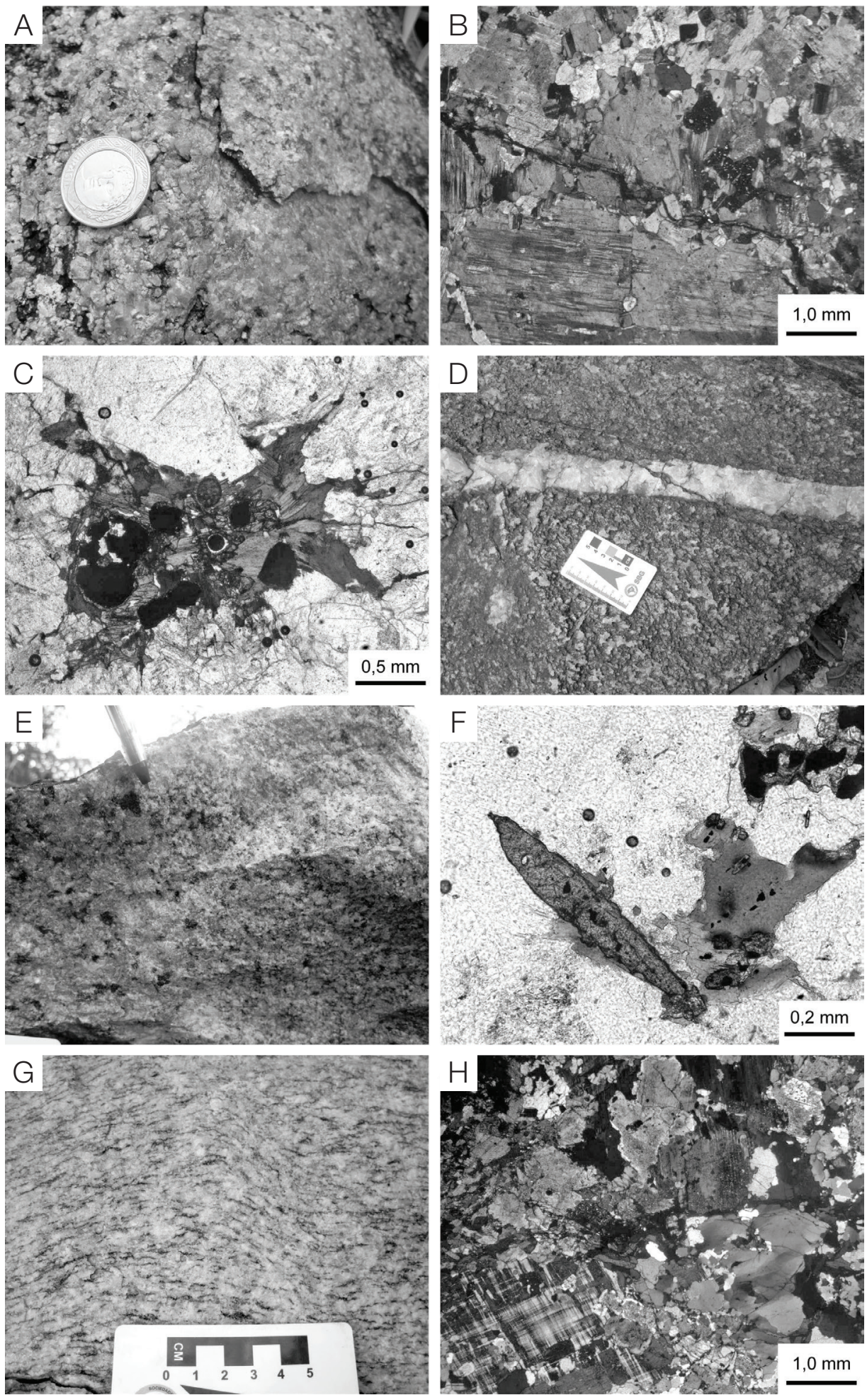

Figura 2. (A) Aspecto macroscópico da fácies cinza rosada do Granito Aragão; (B) textura inequigranular e feldspato alcalino pertítico com inclusões de plagioclásio; (C) agregados de biotita, hornblenda e magnetita na fácies cinza rosada do Granito Aragão; (D) aspecto macroscópico da fácies cinza-clara dos granitoides isotrópicos do Complexo Cuiú-Cuiú, cortados por veios de quartzo; (E) contato transicional entre as fácies cinza rosada e cinza-clara; (F) titanita euédricas associadas à biotita em granitoide da fácies cinza rosada; $(\mathrm{G})$ aspecto macroscópico da fácies equigranular média foliada do Complexo Cuiú-Cuiú; $(H)$ aspecto microscópico da fácies equigranular média foliada evidenciando a ocorrência restrita de processos de deformação no estado sólido e o alinhamento dos agregados de minerais máficos. 
substituídos por clorita. Possuem dimensões de até 2,0 mm e geralmente formam agregados com minerais opacos (magnetita) (Figura 2C). A cor da biotita varia de castanho-clara a verde. A magnetita possui formas subédricas hexagonais, com dimensões de até $1,5 \mathrm{~mm}$. Os cristais de zircão são subédricos de hábito prismático e dimensões inferiores a $0,04 \mathrm{~mm}$. A titanita é rara e ocorre como cristais anédricos. Os minerais de alteração ocorrem de forma bastante subordinada e são representados por micas brancas, principalmente como produto de alteração do plagioclásio, além de epidoto e clorita, esta a partir da substituição dos minerais máficos.

\section{Fácies inequigranular cinza-clara: Complexo Cuiú-Cuiú}

As rochas desta fácies possuem cor cinza-clara, são faneríticas inequigranulares média a grossa e têm conteúdo de minerais máficos entre 10 e 15\% (Figuras 2D e 2E). São constituídas por plagioclásio $(40 \%)$, quartzo $(25 \%)$, feldspato alcalino $(30 \%)$, biotita $(7 \%)$ e hornblenda (5\%), além de minerais acessórios, como titanita, minerais opacos, zircão e apatita em quantidades inferiores a $1 \%$.

O plagioclásio ocorre como cristais subédricos a euédricos de hábito tabular, com dimensões de até $2,5 \mathrm{~mm}$. O feldspato alcalino é subédrico a anédrico, com dimensões entre 2,0 e $8,0 \mathrm{~mm}$. Os cristais de feldspato alcalino apresentam dominantemente macla tartan e subordinadamente macla simples, ou ausência de macla. Intercrescimentos pertíticos são comuns e raramente são observadas inclusões de plagioclásio. A biotita é de cor verde a castanho-clara, com hábito lamelar e dimensões de até 1,0 $\mathrm{mm}$. Localmente, está substituída por clorita e forma agregados com hornblenda e titanita. A hornblenda possui dimensões em torno de 1,0 mm e ocorre como cristais subédricos a euédricos. Os minerais acessórios consistem dominantemente de titanita com formas euédricas a subédricas losangulares de até $0,9 \mathrm{~mm}$ (Figura 2F). Zircão com hábito prismático e euédrico, opacos subédricos a anédricos e apatita prismática subédrica também compõem a mineralogia acessória. Os minerais secundários estão associados à alteração hidrotermal moderada do plagioclásio (micas brancas e epidoto) e à substituição parcial da biotita e da hornblenda por clorita.

\section{Fácies equigranular média foliada: Complexo Cuiú-Cuiú}

Os granitoides desta fácies possuem cor cinza-clara, são equigranulares médios e exibem foliação penetrativa marcada pela orientação de agregados de minerais máficos (Figura 2G). São constituídos por 35\% de feldspato alcalino, $25 \%$ de plagioclásio, $30 \%$ de quartzo e $10 \%$ de biotita, além de minerais acessórios em quantidades inferiores a $1 \%$.
O feldspato alcalino é subédrico a anédrico, com dimensões em torno de $2,5 \mathrm{~mm}$ e frequentes pertitas em flama. Dominam cristais não maclados e, subordinadamente, cristais com macla xadrez. O plagioclásio é subédrico e suas dimensões variam de 1,0 a $2,0 \mathrm{~mm}$. O quartzo possui dimensões próximas a $1,0 \mathrm{~mm}$ e formas anédricas. A extinção ondulante do quartzo varia desde muito fraca até intensa, evidenciando processos restritos de deformação no estado sólido. Não são observadas feições de recristalização no estado sólido do quartzo, como textura granoblástica. Os cristais de biotita possuem hábito lamelar característico, formas subédricas, cor marrom e dimensões de 0,5 a $1,5 \mathrm{~mm}$. Os agregados de biotita, quando alinhados, marcam a foliação (Figura 2H). Zircão e apatita de hábito prismático e formas subédricas, além de minerais opacos anédricos, representam a mineralogia acessória da fácies. Os processos de alteração hidrotermal são subordinados e se restringem à substituição parcial do plagioclásio por mica branca e, raramente, por epidoto.

\section{GEOCRONOLOGIA}

Foram coletadas quatro amostras para as análises geocronológicas pelo método U-Pb em zircão por SHRIMP: duas da fácies inequigranular cinza rosada (SD3 e SD5), uma da fácies inequigranular cinza-clara (SD18) e uma da fácies equigranular média foliada (SD20). Os dados isotópicos dessas amostras são apresentados na Tabela 1. Os teores de ${ }^{206} \mathrm{~Pb}$ comum dos zircões analisados são geralmente inferiores a $0,1 \mathrm{ppm}$, com alguns poucos cristais chegando a 0,3 $\mathrm{ppm}$. As razões Th/U são típicas de zircões de origem ígnea e variam entre 0,04 e 1,51 para os zircões das amostras SD3 e SD5 (fácies inequigranular cinza rosada), entre 0,36 e 1,71 para a amostra SD18 (fácies inequigranular cinza-clara) e de 0,09 a 1,16 para a amostra SD20 (fácies equigranular média foliada). Os valores de discordância de todos os cristais de zircão analisados variam geralmente entre $-1,6$ e $6,9 \%$, chegando a -7,4 e 10,2\% em alguns cristais.

Os cristais de zircão provenientes da amostra SD5 são euédricos a subédricos, com hábito prismático alongado e curto, e dimensões entre 200 e $250 \mu \mathrm{m}$ (Figura 3A). Apresentam fraco zoneamento composicional normal, algumas vezes ausente. Na amostra SD3, os cristais são dominantemente constituídos por prismas curtos, de formas euédricas a subédricas, com frequente zoneamento composicional oscilatório e dimensões em torno de $200 \mu \mathrm{m}$ (Figura 3B). O zircão da amostra SD20 é dominantemente subédrico, de hábito prismático curto a alongado e dimensões entre 100 e $200 \mu \mathrm{m}$. A estruturação de alguns desses cristais indica a presença de núcleos herdados, não zonados, com bordas de crescimento com zoneamento oscilatório característico. Em cristais em que não se observam núcleos herdados, o zoneamento composicional é geralmente normal (Figura 3C). 
Na amostra SD3 (Granito Aragão) foram identificadas duas populações de zircão:

- uma forneceu idade de $1964 \pm 11 \mathrm{Ma}(\mathrm{MSWD}=2,5$; $\mathrm{n}=5$ );

- outra forneceu idade de $2007 \pm 10 \mathrm{Ma}(\mathrm{MSWD}=1,06$; $\mathrm{n}=4$ ) (Figura 4A).
A amostra SD5, também da fácies cinza rosada, forneceu idade de $1967 \pm 2 \mathrm{Ma}(\mathrm{MSWD}=1,6 ; \mathrm{n}=6)$ (Figura 4B). Essa idade se sobrepõe à idade mais jovem da amostra SD3, sendo ambas interpretadas como a idade de cristalização da fácies inequigranular cinza rosada (Granito Aragão). A idade da amostra SD18 (fácies inequigranular cinza-clara,

Tabela 1. Resultados analíticos U-Pb (SHRIMP).

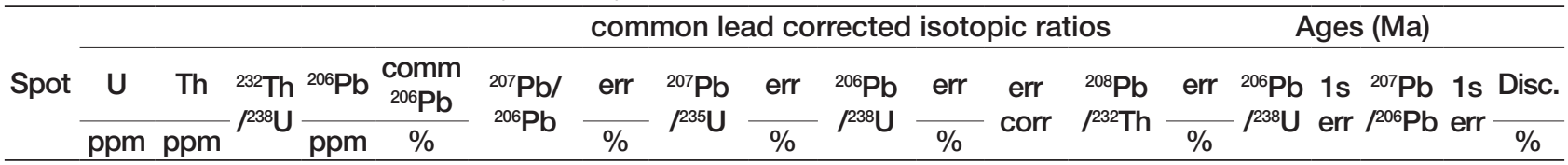

SD-05 - Fácies inequigranular cinza rosada, Granito Aragão, Suíte Intrusiva Nhandú

$\begin{array}{lllllllllllllllllllllll}\text { e.1-1 } 1338 & 1529 & 1,18 & 390 & 0,015 & 0,12070 & 0,38 & 5,6434 & 0,86 & 0,3391 & 0,77 & 0,899 & 0,0943 & 0,89 & 1882 & 13 & 1967 & 7 & 4,9\end{array}$ $\begin{array}{lllllllllllllllllllllllllll}\text { e.1-2 } & 560 & 567 & 1,05 & 159 & 0,000 & 0,12024 & 0,61 & 5,4825 & 1,14 & 0,3307 & 0,96 & 0,843 & 0,0906 & 1,56 & 1842 & 15 & 1960 & 11 & 6,9\end{array}$ e.2-1 $16442396 \begin{array}{llllllllllllllllllll}1,51 & 518 & 0,000 & 0,12055 & 0,25 & 6,0928 & 0,47 & 0,3666 & 0,40 & 0,842 & 0,1012 & 0,47 & 2013 & 7 & 1964 & 5 & -2,5\end{array}$

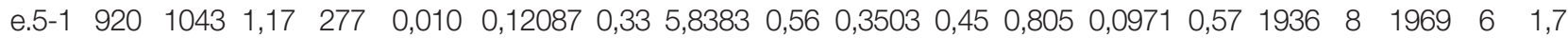

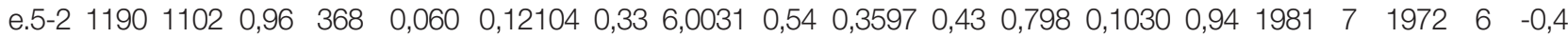
e.6-1 $11951319 \begin{array}{lllllllllllllllllllllll}1,14 & 365 & 0,000 & 0,12079 & 0,29 & 5,9258 & 0,53 & 0,3558 & 0,44 & 0,831 & 0,0963 & 0,54 & 1962 & 7 & 1968 & 5 & 0,3\end{array}$

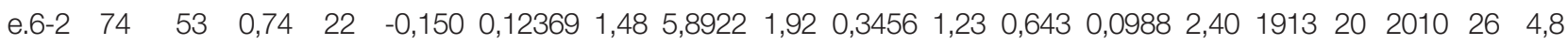
SD-03 - Fácies inequigranular cinza rosada, Granito Aragão, Suíte Intrusiva Nhandú

$\begin{array}{llllllllllllllllllllllll}\text { f.1-1 } & 676 & 25 & 0,04 & 196 & 0,050 & 0,12084 & 0,68 & 5,6337 & 1,04 & 0,3381 & 0,79 & 0,760 & 0,0894 & 8,84 & 1877 & 1369 & 12 & 4,6\end{array}$ $\begin{array}{lllllllllllllllllllllll}\text { f.1-2 } & 119 & 108 & 0,94 & 35 & 0,000 & 0,12338 & 0,83 & 5,9241 & 1,44 & 0,3482 & 1,18 & 0,817 & 0,0985 & 1,56 & 1926 & 2006 & 15 & 4,6\end{array}$ $\begin{array}{llllllllllllllllllllllllll}\text { f.1-3 } & 97 & 108 & 1,15 & 28 & 0,000 & 0,12032 & 0,94 & 5,6719 & 1,60 & 0,3419 & 1,30 & 0,811 & 0,0941 & 1,69 & 1896 & 21 & 1961 & 17 & 3,8\end{array}$ $\begin{array}{llllllllllllllllllllllllll}\text { f.2-1 } & 368 & 45 & 0,13 & 108 & 0,110 & 0,11935 & 0,92 & 5,6114 & 1,31 & 0,3409 & 0,93 & 0,716 & 0,0894 & 4,64 & 1891 & 15 & 1947 & 16 & 2,9\end{array}$

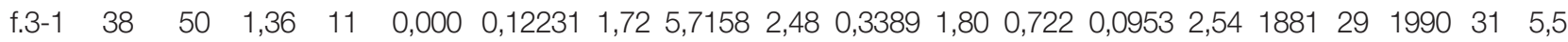

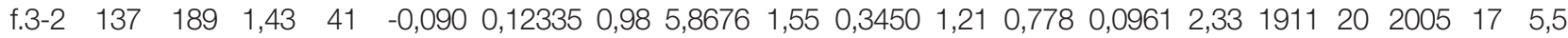
$\begin{array}{lllllllllllllllllllllllll}\text { f.4-1 } & 54 & 42 & 0,79 & 16 & 0,000 & 0,12475 & 1,47 & 5,8426 & 2,12 & 0,3397 & 1,53 & 0,722 & 0,1020 & 2,33 & 1885 & 25 & 26 & 6,9\end{array}$

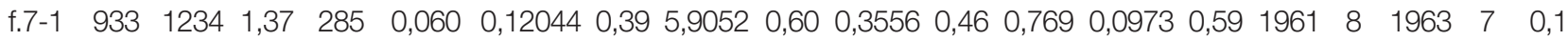

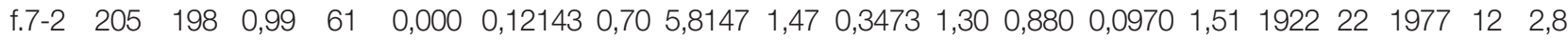
SD-20 - Fácies equigranular média foliada, Complexo Cuiú-Cuiú

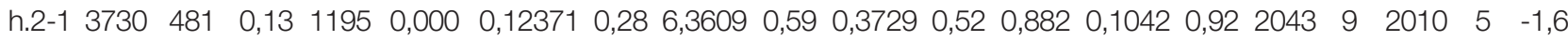

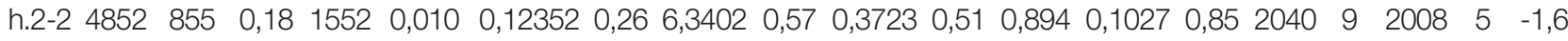

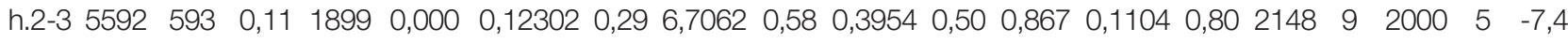
$\begin{array}{lllllllllllllllllllllllllll}\text { h.2-4 } & 68 & 21 & 0,31 & 21 & 0,322 & 0,12277 & 1,25 & 5,9825 & 1,92 & 0,3534 & 1,46 & 0,757 & 0,0946 & 3,77 & 1951 & 24 & 1997 & 22 & 2,7\end{array}$

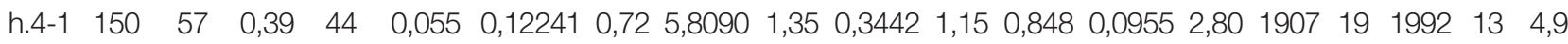

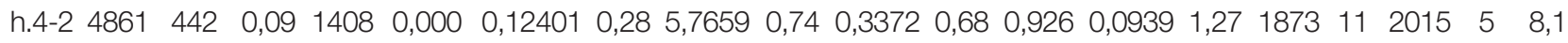

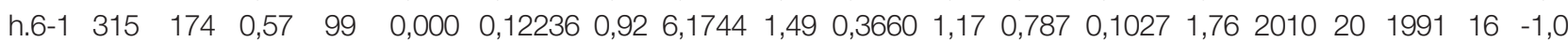

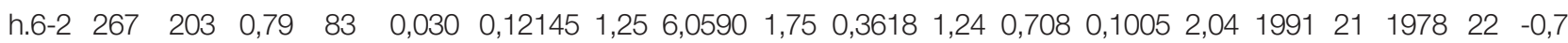
h.6-3 $362105 \quad 0,30108 \quad 0,090 \quad 0,126430,88$ 6,0620 1,30 0,3477 0,96 0,741 0,0967 2,23 $1924 \quad 162049 \quad 15 \quad 6,1$

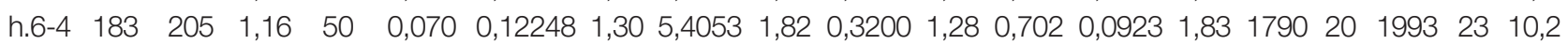
h.8-1 $87 \quad 23 \quad 0,27 \quad 26 \quad-0,090 \quad 0,12472 \quad 1,00 \quad 5,8537 \quad 1,64 \quad 0,3404$ 1,30 0,795 0,0998 2,84 $1889212025 \quad 18 \quad 7,8$ SD-18 - Fácies inequigranular cinza-clara, Complexo Cuiú-Cuiú

$\begin{array}{llllllllllllllllllllll}\text { c.4-1 } & 270 & 376 & 1,43 & 81 & 0,067 & 0,12183 & 0,82 & 5,859 & 1,50 & 0,3488 & 1,26 & 0,839 & 0,0996 & 1,52 & 1929 & 21 & 1983 & 15 & 3,2\end{array}$ $\begin{array}{llllllllllllllllllllllllll}\text { c.4-2 } & 331 & 548 & 1,71 & 102 & 0,109 & 0,12228 & 1,22 & 6,019 & 1,60 & 0,3570 & 1,04 & 0,651 & 0,1013 & 1,27 & 1968 & 18 & 1990 & 22 & 1,3\end{array}$ $\begin{array}{llllllllllllllllllllllllll}\text { c.5-1 } & 251 & 87 & 0,36 & 75 & 0,077 & 0,12176 & 0,76 & 5,862 & 1,34 & 0,3492 & 1,11 & 0,823 & 0,0945 & 2,25 & 1931 & 18 & 1982 & 14 & 3,0\end{array}$ $\begin{array}{lllllllllllllllllllllll}\text { c.5-2 } & 555 & 143 & 0,27 & 164 & 0,060 & 0,12240 & 0,67 & 5,817 & 1,23 & 0,3447 & 1,04 & 0,842 & 0,0962 & 1,92 & 1909 & 17 & 1991 & 12 & 4,8\end{array}$ $\begin{array}{llllllllllllllllllllllllll}\text { c.5-3 } & 563 & 174 & 0,32 & 169 & 0,028 & 0,12137 & 0,63 & 5,836 & 1,20 & 0,3487 & 1,02 & 0,853 & 0,0949 & 1,66 & 1929 & 17 & 1976 & 11 & 2,8\end{array}$

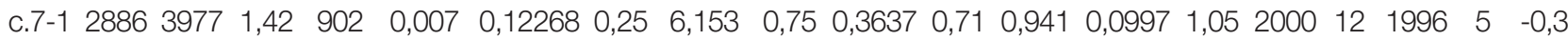
$\begin{array}{clllllllllllllllllllllllll}\text { c.8-1 } & 542 & 465 & 0,89 & 161 & 0,111 & 0,12161 & 0,64 & 5,809 & 1,20 & 0,3465 & 1,01 & 0,846 & 0,0979 & 1,30 & 1918 & 17 & 1980 & 11 & 3,6\end{array}$ $\begin{array}{llllllllllllllllllllllllll}\text { c.9-1 } & 349 & 363 & 1,07 & 105 & 0,185 & 0,12241 & 1,05 & 5,921 & 1,75 & 0,3508 & 1,41 & 0,803 & 0,0960 & 1,87 & 1939 & 24 & 1992 & 19 & 3,1\end{array}$ $\begin{array}{llllllllllllllllllllllll}\text { c.6-1 } & 338 & 268 & 0,82 & 97 & 0,062 & 0,12109 & 0,96 & 5,593 & 1,70 & 0,3350 & 1,41 & 0,827 & 0,0932 & 1,90 & 1862 & 23 & 1972 & 17 & 6,4\end{array}$ 
Complexo Cuiú-Cuiú) é de $1995 \pm 5 \mathrm{Ma}$, (MSWD = 0,78; $n=9$ ) (Figura 4C), enquanto a amostra SD20 (fácies equigranular média foliada, Complexo Cuiú-Cuiú) tem idade de $2009 \pm 4 \mathrm{Ma}(\mathrm{MSWD}=2,8 ; \mathrm{n}=9)$ (Figura 4D). As idades das amostras SD18 e SD20, bem como a idade dos núcleos herdados da amostra SD3, são similares, considerando a margem de erro. Dessa forma, a idade mais antiga da amostra SD3 é interpretada como idade herdada e pode representar a idade da fonte dos magmas que originaram os granitoides ou ser oriunda de contaminação da encaixante. A idade da amostra SD20 coincide com as idades de ortognaisses e granitoides do Complexo Cuiú-Cuiú na PMT. A idade de $2009 \pm 4 \mathrm{Ma}$, obtida para a amostra SD20, é próxima à idade de $1992 \pm 7 \mathrm{Ma}$, obtida para o ortognaisse granítico

\section{A}
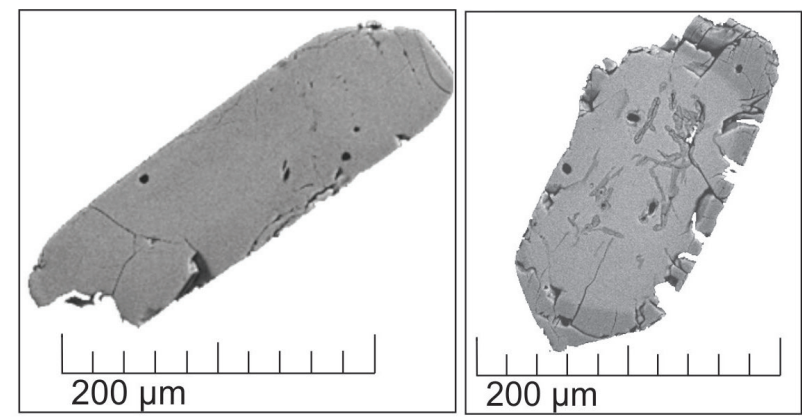

B
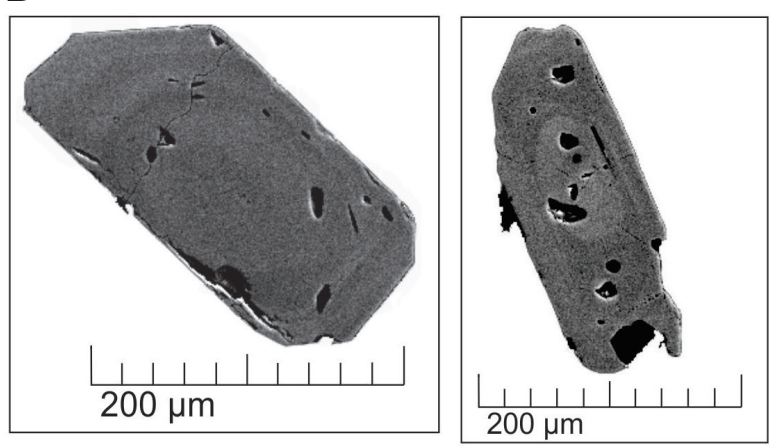

C
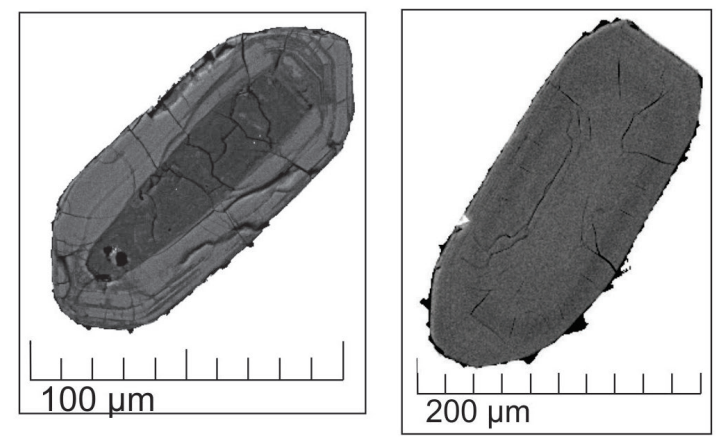

Figura 3. Imagens de elétrons retroespalhados de cristais de zircão provenientes das amostras: (A) SD5; (B) SD3; (C) SD-20.
(Souza et al., 2005), e $1980 \pm 8 \mathrm{Ma}$, para o Gnaisse Nova Guarita (Assis, 2015), pertencentes ao Complexo Cuiú-Cuiú na PAAF. A idade de $2036 \pm 8$ Ma obtida por Deitos et al. (2016) para biotita gnaisse granodiorítico, também atribuído ao Complexo Cuiú-Cuiú, é significativamente mais antiga.

A idade de cristalização do Granito Aragão (SD3: $1964 \pm$ $11 \mathrm{Ma}$ ) é compatível com as idades de $1970 \pm 3,1964 \pm 1 \mathrm{e}$ $1956 \pm 12$ obtidas por Paes de Barros (2007) para o Granito Novo Mundo da PAAF. Barros et al. (2015) obtiveram idades de $1963 \pm 7$ e $1954 \pm 6$ Ma na seção-tipo do Granito Nhandú na PAAF e definiram que os granitoides que compõem a SINH devem possuir idades semelhantes, inclusive os granitoides da região do Garimpo Trairão, que possuem idades de cristalização de $1987 \pm 12$ e $1946 \pm 8$ Ma, de acordo com dados obtidos por Rocha et al. (2015).

A SIC, da PMT, possui idades de cristalização de $1997 \pm$ $3 \mathrm{Ma}$ e $1957 \pm 6 \mathrm{Ma}$, segundo dados apresentados por Vasquez et al. (2002) e Santos et al. (2000). Levando-se em conta os intervalos de idades e os erros analíticos das amostras da SIC e da SINH, propõe-se no presente trabalho uma correlação cronoestratigráfica entre essas unidades.

\section{GEOQUÍMICA}

A geoquímica em rocha total foi realizada em três amostras da fácies inequigranular cinza-clara (granitoides isotrópicos do Complexo Cuiú-Cuiú) e em oito da fácies inequigranular cinza rosada (Granito Aragão) (Tabela 2). As amostras dos granitoides isotrópicos do Complexo Cuiú-Cuiú se caracterizam por menor conteúdo de $\mathrm{SiO}_{2}$, com valores entre 66,52 e $69,68 \%$, enquanto as amostras do Granito Aragão possuem valores entre 68,74 e $76,83 \%$. Os granitoides isotrópicos do Complexo Cuiú-Cuiú possuem conteúdos mais elevados de $\mathrm{Al}_{2} \mathrm{O}_{3}, \mathrm{MgO}, \mathrm{CaO}, \mathrm{Ba}$ e $\mathrm{Sr}$, e mais baixos de $\mathrm{K}_{2} \mathrm{O}$ e $\mathrm{Nb}$, quando comparados ao Granito Aragão.

Para fins de comparação com o Granito Aragão, foram compilados os dados geoquímicos da SIC apresentados por Vasquez et al. (2002), conforme a Tabela 3.

Em diagramas binários utilizando $\mathrm{SiO}_{2}$ como índice de diferenciação, observam-se algumas similaridades entre as amostras do Granito Aragão e da SIC. A distribuição dos elementos para essas duas unidades aponta para correlações negativas entre o índice de diferenciação e $\mathrm{Al}_{2} \mathrm{O}_{3}, \mathrm{CaO}$, $\mathrm{MgO}, \mathrm{TiO}_{2}$, Ba e Sr, sugerindo processos de fracionamento de fases minerais como plagioclásio, hornblenda e óxidos de $\mathrm{Fe}-\mathrm{Ti}$. A distribuição dos elementos dos granitoides isotrópicos do Complexo Cuiú-Cuiú ilustra as diferenças composicionais entre essas rochas e aquelas do Granito Aragão e da SIC, conforme salientado anteriormente (Figuras 5 e 6).

A distribuição de elementos maiores e de elementos-traço em diagramas multielementos evidencia as diferenças entre as rochas do Granito Aragão e da SIC, quando comparadas 
àquelas dos granitoides isotrópicos do Complexo Cuiú-Cuiú. As amostras do Granito Aragão possuem fortes anomalias negativas de $\mathrm{Ba}, \mathrm{Nb}, \mathrm{Ta}, \mathrm{Sr}, \mathrm{P}$, Ti e Eu, enquanto essas anomalias são menos pronunciadas nas amostras da SIC. Ambos os granitos possuem moderado empobrecimento de elementos terras raras leves e fraco empobrecimento de elementos terras raras pesados (Figuras 7A a 7D). As amostras dos granitoides isotrópicos do Complexo Cuiú-Cuiú possuem anomalias negativas de $\mathrm{Nb}, \mathrm{Ta}, \mathrm{Pe}$ Ti menos pronunciadas e anomalias negativas fracas de $\mathrm{Ba}, \mathrm{Sr}$ e $\mathrm{Eu}$, inexistentes em algumas amostras (Figuras 7E e 7F). Esses padrões de distribuição sugerem afinidade com granitos tipo-A para as amostras do Granito Aragão e da SIC, enquanto os granitoides isotrópicos do Complexo Cuiú-Cuiú possuem padrão semelhante ao de granitoides shoshoníticos, com empobrecimento em elementos terras raras pesados e ausência de anomalia negativa de Eu, de acordo com Morrison (1980).

As rochas dos granitoides isotrópicos do Complexo Cuiú-Cuiú são classificadas, no diagrama $\mathrm{R} 1$ versus $\mathrm{R} 2$ (Figura 8A), como granodioritos e quartzo monzonitos. Os litotipos do Granito Aragão são classificados preferencialmente como feldspato alcalino granitos, com granitos s.s. e quartzo sienitos subordinados. As rochas da SIC ocupam dominantemente o campo dos granitos s.s., com granodioritos subordinados. Todas as litologias possuem caráter metaluminoso a fracamente peraluminoso (Figura 8B). O caráter ferroso das amostras do Granito Aragão e da SIC, conforme indicado pelos conteúdos de $\mathrm{FeO}^{\mathrm{t}} /\left(\mathrm{FeO}^{\mathrm{t}}+\mathrm{MgO}\right)$ no diagrama de Frost et al. (2001), sugere afinidade com granitos tipo-A. As amostras dos granitoides isotrópicos do
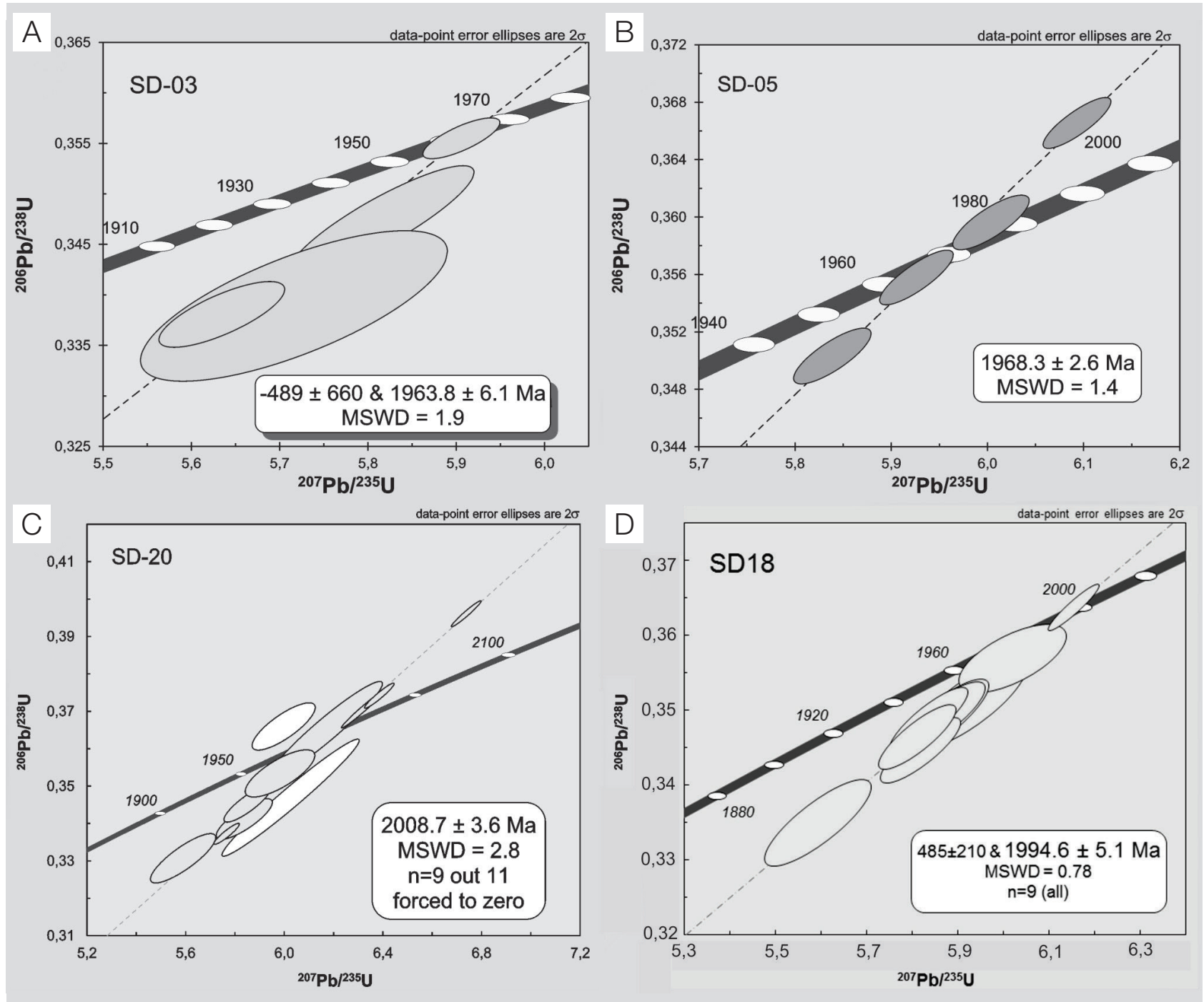

Figura 4. Diagramas concórdia U-Pb para as amostras SD3 (A) e SD5 (B), que mostram idades de cristalização de 1964 \pm 11 Ma e $1967 \pm 2$ Ma; SD-18 (D) com idade de $1994 \pm 5$ Ma; e SD-20 (C) com idade de $2008 \pm 3$ Ma. 
Tabela 2. Dados geoquímicos das fácies inequigranulares cinza rosada (Granito Aragão) e cinza-clara (Complexo Cuiú-Cuiú) (elementos maiores expressos em \% em peso e elementos-traço expressos em ppm).

\begin{tabular}{|c|c|c|c|c|c|c|c|c|c|c|c|}
\hline & \multicolumn{8}{|c|}{ Granito Aragão } & \multicolumn{3}{|c|}{ Complexo Cuiú-Cuiú } \\
\hline & SD-02 & SD-03 & SD-04 & SD-08 & SD-11B & SD-15 & SD-17 & SD-19 & SD-06 & SD-07 & SD-18 \\
\hline $\mathrm{SiO}_{2}$ & 76,83 & 68,74 & 75,26 & 70,16 & 74,98 & 75,33 & 75,27 & 75,89 & 69,68 & 68,47 & 66,52 \\
\hline $\mathrm{Al}_{2} \mathrm{O}_{3}$ & 11,49 & 14,63 & 12,34 & 14,04 & 12,55 & 12,32 & 13,19 & 11,84 & 15,17 & 15,86 & 15,80 \\
\hline $\mathrm{FeO}$ & 2,02 & 3,07 & 2,24 & 2,78 & 1,48 & 1,79 & 1,42 & 1,76 & 3,06 & 2,76 & 3,29 \\
\hline $\mathrm{Fe}_{2} \mathrm{O}_{3}$ & 2,24 & 3,41 & 2,49 & 3,09 & 1,64 & 1,99 & 1,58 & 1,96 & 3,40 & 3,07 & 3,65 \\
\hline $\mathrm{MgO}$ & 0,11 & 0,41 & 0,05 & 0,41 & 0,19 & 0,09 & 0,12 & 0,13 & 0,68 & 0,79 & 0,90 \\
\hline $\mathrm{CaO}$ & 0,46 & 1,05 & 0,08 & 0,79 & 0,34 & 0,47 & 0,48 & 0,32 & 2,18 & 2,59 & 2,53 \\
\hline $\mathrm{Na}_{2} \mathrm{O}$ & 2,77 & 4,18 & 4,37 & 3,99 & 2,99 & 3,15 & 4,25 & 3,17 & 4,67 & 4,22 & 4,63 \\
\hline $\mathrm{K}_{2} \mathrm{O}$ & 5,42 & 6,04 & 4,51 & 6,06 & 6,07 & 5,59 & 4,60 & 5,58 & 2,79 & 3,5 & 4,08 \\
\hline $\mathrm{TiO}_{2}$ & 0,19 & 0,58 & 0,17 & 0,51 & 0,33 & 0,19 & 0,13 & 0,29 & 0,27 & 0,31 & 0,39 \\
\hline $\mathrm{P}_{2} \mathrm{O}_{5}$ & 0,02 & 0,08 & 0,01 & 0,09 & 0,03 & 0,02 & $<0,01$ & 0,03 & 0,09 & 0,11 & 0,12 \\
\hline $\mathrm{MnO}$ & 0,04 & 0,11 & 0,04 & 0,10 & 0,06 & 0,04 & 0,03 & 0,06 & 0,08 & 0,05 & 0,09 \\
\hline Sc & 4,00 & 10,00 & 4,00 & 9,00 & 3,00 & 4,00 & 2,00 & 6,00 & 4,00 & 3,00 & 4,00 \\
\hline LOI & 0,30 & 0,50 & 0,60 & 0,50 & 0,70 & 0,70 & 0,30 & 0,60 & 0,80 & 0,70 & 1,00 \\
\hline Total & 99,86 & 99,72 & 99,92 & 99,74 & 99,90 & 99,91 & 99,93 & 99,89 & 99,80 & 99,69 & 99,72 \\
\hline $\mathrm{Ba}$ & 302,00 & 845,00 & 58,00 & 626,00 & 361,00 & 275,00 & 316,00 & 181,00 & 771,00 & 1685,00 & 1407,00 \\
\hline Co & 0,80 & 1,90 & $<0,20$ & 1,50 & 0,40 & 0,60 & 0,70 & 0,40 & 4,00 & 4,50 & 5,00 \\
\hline CS & 1,10 & 0,70 & 0,10 & 1,00 & 0,40 & 1,30 & 0,80 & 1,10 & 3,60 & 3,90 & 2,20 \\
\hline Ga & 13,70 & 18,50 & 18,30 & 17,10 & 14,30 & 14,40 & 14,60 & 13,60 & 20,80 & 15,20 & 17,40 \\
\hline $\mathrm{Hf}$ & 7,10 & 14,90 & 8,40 & 13,80 & 8,00 & 5,90 & 4,60 & 7,50 & 5,40 & 4,10 & 5,00 \\
\hline $\mathrm{Nb}$ & 70 & 12,90 & 6,80 & 13,10 & 11,80 & 7,60 & 9,90 & 17,60 & 10,20 & 6,10 & 5,80 \\
\hline $\mathrm{Rb}$ & 109,30 & 104,40 & 67,10 & 129,40 & 128,70 & 109,00 & 88,90 & 149,20 & 108,00 & 93,60 & 132,10 \\
\hline $\mathrm{Sr}$ & 35,80 & 107,20 & 11,80 & 78,60 & 60,10 & 35,80 & 53,20 & 17,80 & 427,60 & 651,30 & 493,70 \\
\hline $\mathrm{Ta}$ & 0,40 & 0,60 & 0,40 & 0,70 & 0,70 & 0,40 & 0,90 & 1,60 & 0,90 & 0,80 & 0,40 \\
\hline Th & 20,10 & 11,70 & 4,80 & 13,50 & 5,50 & 9,10 & 13,00 & 8,70 & 14,20 & 9,20 & 7,50 \\
\hline U & 1,20 & 0,90 & 0,20 & 1,20 & 0,60 & 1,30 & 2,00 & 1,30 & 4,30 & 1,70 & 3,20 \\
\hline $\mathrm{Zr}$ & 267,30 & 656,00 & 388,20 & 598,60 & 323,30 & 228,10 & 143,90 & 311,80 & 178,90 & 162,50 & 205,50 \\
\hline Y & 21,30 & 35,50 & 19,30 & 38,70 & 12,10 & 20,60 & 20,90 & 50,40 & 17,00 & 11,50 & 12,60 \\
\hline $\mathrm{La}$ & 122,70 & 157,00 & 52,20 & 150,00 & 30,80 & 63,30 & 30,40 & 82,60 & 54,00 & 27,60 & 45,30 \\
\hline $\mathrm{Ce}$ & 235,70 & 292,60 & 69,30 & 259,70 & 52,40 & 113,70 & 63,40 & 161,90 & 99,80 & 61,20 & 88,80 \\
\hline $\operatorname{Pr}$ & 24,57 & 30,46 & 13,30 & 29,01 & 5,95 & 12,48 & 6,39 & 19,04 & 9,17 & 5,36 & 9,45 \\
\hline $\mathrm{Nd}$ & 86,30 & 106,70 & 49,70 & 101,40 & 20,60 & 44,10 & 22,20 & 66,80 & 30,00 & 19,00 & 33,40 \\
\hline Sm & 11,10 & 15,14 & 9,78 & 14,03 & 2,99 & 6,83 & 4,33 & 11,19 & 4,34 & 3,42 & 5,20 \\
\hline Eu & 0,62 & 2,14 & 0,62 & 2,04 & 0,47 & 0,55 & 0,37 & 1,00 & 0,83 & 0,88 & 1,12 \\
\hline $\mathrm{Gd}$ & 7,04 & 10,44 & 7,41 & 10,89 & 2,22 & 5,46 & 3,77 & 9,18 & 3,53 & 2,62 & 3,81 \\
\hline $\mathrm{Tb}$ & 0,82 & 1,31 & 1,10 & 1,32 & 0,28 & 0,73 & 0,64 & 1,60 & 0,50 & 0,40 & 0,50 \\
\hline Dy & 3,83 & 6,91 & 5,66 & 6,62 & 1,56 & 3,94 & 3,62 & 9,46 & 2,72 & 2,05 & 2,57 \\
\hline $\mathrm{Ho}$ & 0,69 & 1,26 & 0,96 & 1,32 & 0,32 & 0,74 & 0,71 & 1,87 & 0,55 & 0,40 & 0,45 \\
\hline Er & 1,84 & 3,42 & 2,41 & 3,58 & 1,11 & 2,00 & 2,16 & 5,21 & 1,62 & 1,12 & 1,24 \\
\hline Tm & 0,27 & 0,55 & 0,33 & 0,53 & 0,19 & 0,30 & 0,32 & 0,77 & 0,27 & 0,18 & 0,17 \\
\hline $\mathrm{Yb}$ & 1,6 & 3,56 & 1,90 & 3,52 & 1,20 & 1,94 & 2,05 & 4,46 & 1,58 & 1,15 & 1,10 \\
\hline Lu & 0,27 & 0,61 & 0,28 & 0,60 & 0,24 & 0,29 & 0,30 & 0,61 & 0,27 & 0,17 & 0,17 \\
\hline Mo & 1,10 & 0,30 & 0,10 & 0,30 & 0,20 & 0,50 & 0,20 & 0,20 & 0,30 & 0,20 & 0,90 \\
\hline $\mathrm{Cu}$ & 8,00 & 2,70 & 1,30 & 2,60 & 7,80 & 1,60 & 1,70 & 1,90 & 10,20 & 2,90 & 25,70 \\
\hline $\mathrm{Pb}$ & 23,20 & 21,90 & 6,50 & 21,90 & 10,90 & 18,40 & 15,00 & 17,40 & 15,50 & 8,80 & 11,80 \\
\hline $\mathrm{Zn}$ & 55,00 & 82,00 & 50,00 & 76,00 & 24,00 & 39,00 & 19,00 & 41,00 & 68,00 & 49,00 & 66,00 \\
\hline $\mathrm{Ni}$ & 4,60 & 1,20 & 0,80 & 1,40 & 0,70 & 0,90 & 0,70 & 0,5 & 3,40 & 3,30 & 3,30 \\
\hline $\mathrm{Au}$ & 2,80 & 1,50 & 2,00 & 1,50 & 2,50 & $<0,50$ & $<0.50$ & $<0,50$ & 1,80 & 1,20 & 1,70 \\
\hline
\end{tabular}


Complexo Cuiú-Cuiú se posicionam próximo ao limite entre os campos de granitos ferrosos e magnesianos (Figura 8C).

Segundo a classificação geoquímica de granitos, o Granito Aragão e a SIC ocupam dominantemente o campo dos granitos tipo-A nos diagramas de Whalen et al. (1987), com algumas amostras enquadradas no campo de granitos tipo-I e tipo-S fracionados (Figuras 9A e 9B). Destaca-se que, apesar de muitas amostras do Granito Aragão e da SIC apresentarem conteúdos de $\mathrm{Zr}+\mathrm{Nb}+\mathrm{Ce}+\mathrm{Y}$ superiores a $350 \mathrm{ppm}$, valor que caracteriza granitos tipo-A, as razões $\mathrm{Ga} / \mathrm{Al}$ das amostras do Granito Aragão são inferiores a 2,6, valor mínimo para granitos tipo-A. A razão $\mathrm{FeO}^{\text {t/ }}$
$(\mathrm{FeO}+\mathrm{MgO})$, quando comparada aos conteúdos de $\mathrm{Al}_{2} \mathrm{O}_{3}$ no diagrama de Dall'Agnol e Oliveira (2007), indica que as amostras do Granito Aragão ocupam preferencialmente o campo dos granitos tipo-A reduzidos, enquanto as amostras do Complexo Cuiú-Cuiú e da SIC ocupam os campos dos granitos tipo-A oxidados e calcialcalinos (Figura 9C). Os granitoides isotrópicos do Complexo Cuiú-Cuiú ocupam essencialmente o campo de granitos tipo-I e tipo-S, nos diagramas de Whalen et al. (1987), e de granitos calcialcalinos, no diagrama de Dall'Agnol e Oliveira (2007). A subdivisão de Eby (1992) para granitos tipo-A que plotam no campo de granitos tipo-A no diagrama de Whalen

Tabela 3. Dados geoquímicos dos granitoides da Suíte Intrusiva Creporizão, compilados de Vasquez et al. (2002) (elementos maiores expressos em \% em peso e elementos-traço expressos em ppm).

\begin{tabular}{|c|c|c|c|c|c|c|c|c|c|c|}
\hline & MV-74 & HG-02 & HG-08 & HG-11 & HA-90 & EK-41 & EK-54 & MV-30 & EK-39 & HA-12 \\
\hline $\mathrm{SiO}_{2}$ & 57,03 & 62,58 & 65,19 & 69,12 & 70,22 & 70,94 & 71,61 & 72,12 & 72,21 & 73,44 \\
\hline $\mathrm{Al} 2 \mathrm{O}_{3}$ & 16,09 & 15,02 & 14,53 & 14,41 & 13,43 & 14,13 & 12,35 & 13,92 & 12,89 & 12,30 \\
\hline $\mathrm{FeO}$ & 9,80 & 6,70 & 6,09 & 3,66 & 3,93 & 4,37 & 5,53 & 3,76 & 4,66 & 4,14 \\
\hline $\mathrm{MgO}$ & 3,21 & 1,89 & 1,51 & 0,76 & 0,35 & 0,88 & 0,44 & 0,53 & 0,42 & 0,36 \\
\hline $\mathrm{CaO}$ & 5,73 & 4,25 & 3,62 & 2,11 & 1,63 & 2,18 & 1,58 & 1,59 & 1,74 & 1,10 \\
\hline $\mathrm{Na}_{2} \mathrm{O}$ & 3,72 & 3,56 & 3,37 & 3,05 & 3,35 & 3,23 & 3,00 & 3,77 & 3,74 & 3,05 \\
\hline $\mathrm{K}_{2} \mathrm{O}$ & 1,95 & 2,67 & 3,41 & 4,87 & 5,00 & 3,69 & 4,25 & 4,49 & 3,76 & 4,52 \\
\hline $\mathrm{TiO}_{2}$ & 1,00 & 0,96 & 0,75 & 0,41 & 0,33 & 0,37 & 0,38 & 0,32 & 0,41 & 0,27 \\
\hline $\mathrm{P}_{2} \mathrm{O}_{5}$ & 0,23 & 0,30 & 0,23 & 0,15 & 0,11 & 0,19 & 0,24 & 0,08 & 0,16 & 0,08 \\
\hline $\mathrm{MnO}$ & 0,16 & 0,10 & 0,09 & 0,06 & 0,06 & 0,06 & 0,09 & 0,07 & 0,06 & 0,06 \\
\hline $\mathrm{Ba}$ & 1358,00 & 0,00 & 0,00 & 0,00 & 662,00 & 744,00 & 876,00 & 516,00 & 0,00 & 0,00 \\
\hline $\mathrm{Hf}$ & 4,90 & 5,60 & 5,10 & 5,60 & 4,40 & 5,30 & 9,50 & 4,60 & 8,90 & 7,40 \\
\hline $\mathrm{Nb}$ & 10,00 & 17,00 & 20,00 & 24,00 & 23,00 & 15,00 & 21,00 & 12,00 & 16,00 & 24,00 \\
\hline $\mathrm{Rb}$ & 94,00 & 149,00 & 180,00 & 225,00 & 226,00 & 246,00 & 260,00 & 168,00 & 182,00 & 287,00 \\
\hline $\mathrm{Sr}$ & 560,00 & 327,00 & 279,00 & 225,00 & 166,00 & 198,00 & 116,00 & 212,00 & 116,00 & 109,00 \\
\hline Ta & 0,80 & 1,10 & 1,20 & 1,60 & 1,40 & 1,80 & 2,20 & 1,20 & 1,30 & 1,80 \\
\hline Th & 8,70 & 13,10 & 14,40 & 22,90 & 9,70 & 21,80 & 18,80 & 19,60 & 42,90 & 37,60 \\
\hline$U$ & 1,20 & 3,40 & 3,70 & 4,60 & 2,00 & 4,60 & 4,20 & 3,90 & 2,90 & 6,60 \\
\hline $\mathrm{Zr}$ & 175,00 & 264,00 & 234,00 & 232,00 & 255,00 & 177,00 & 331,00 & 145,00 & 302,00 & 250,00 \\
\hline Y & 25,00 & 37,00 & 31,00 & 35,00 & 40,00 & 21,00 & 38,00 & 23,00 & 33,00 & 51,00 \\
\hline La & 39,60 & 47,70 & 48,70 & 51,70 & 37,60 & 42,80 & 46,80 & 46,20 & 135,70 & 55,90 \\
\hline $\mathrm{Ce}$ & 77,30 & 95,20 & 99,20 & 102,50 & 77,60 & 81,60 & 89,50 & 87,80 & 244,60 & 115,40 \\
\hline $\operatorname{Pr}$ & 9,80 & 0,00 & 0,00 & 0,00 & 0,00 & 9,72 & 11,20 & 10,20 & 27,40 & 0,00 \\
\hline $\mathrm{Nd}$ & 39,10 & 0,00 & 0,00 & 0,00 & 0,00 & 33,70 & 41,20 & 35,30 & 90,30 & 0,00 \\
\hline Sm & 7,70 & 8,60 & 7,40 & 8,10 & 6,90 & 6,20 & 8,40 & 6,20 & 13,10 & 8,70 \\
\hline $\mathrm{Eu}$ & 2,10 & 1,80 & 1,40 & 1,20 & 1,40 & 0,90 & 1,20 & 0,90 & 1,40 & 0,80 \\
\hline $\mathrm{Gd}$ & 6,30 & 7,40 & 5,90 & 6,30 & 5,70 & 4,80 & 7,10 & 4,90 & 10,30 & 7,30 \\
\hline $\mathrm{Tb}$ & 0,90 & 0,00 & 0,00 & 0,00 & 0,00 & 0,70 & 1,30 & 0,80 & 1,40 & 0,00 \\
\hline Dy & 5,60 & 6,80 & 5,10 & 5,90 & 5,70 & 4,40 & 7,90 & 4,60 & 8,00 & 7,30 \\
\hline $\mathrm{Ho}$ & 1,00 & 1,30 & 1,00 & 1,10 & 1,10 & 0,80 & 1,30 & 0,80 & 1,40 & 1,50 \\
\hline Er & 2,70 & 3,80 & 2,80 & 3,20 & 3,40 & 2,20 & 3,80 & 2,40 & 3,40 & 4,70 \\
\hline $\mathrm{Tm}$ & 0,40 & 0,00 & 0,00 & 0,00 & 0,00 & 0,40 & 0,60 & 0,40 & 0,50 & 0,00 \\
\hline $\mathrm{Yb}$ & 2,80 & 3,30 & 2,50 & 2,90 & 3,30 & 2,40 & 4,20 & 2,60 & 3,60 & 5,30 \\
\hline $\mathrm{Lu}$ & 0,00 & 0,50 & 0,40 & 0,40 & 0,50 & 0,00 & 0,00 & 0,00 & 0,00 & 0,80 \\
\hline
\end{tabular}



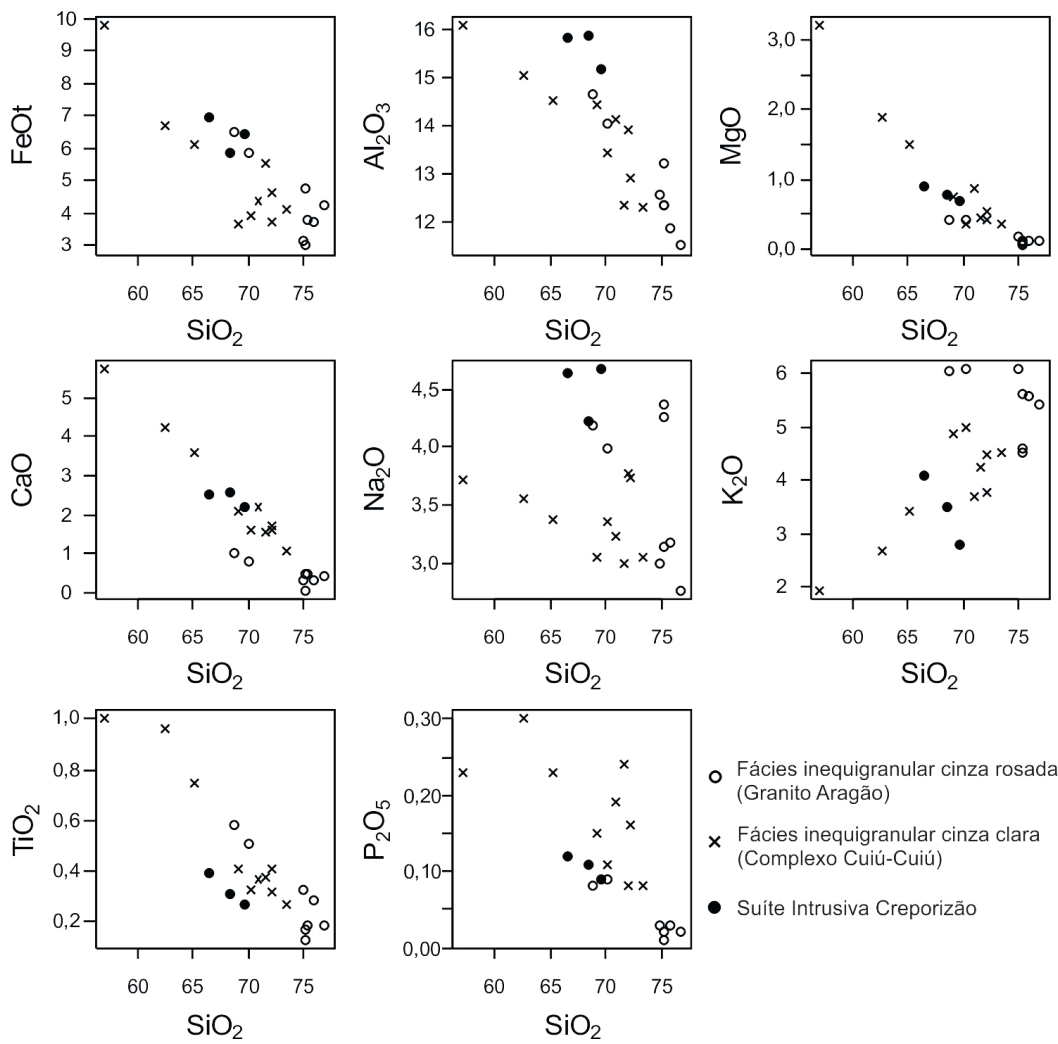

Figura 5. Diagramas de Harker para elementos maiores.
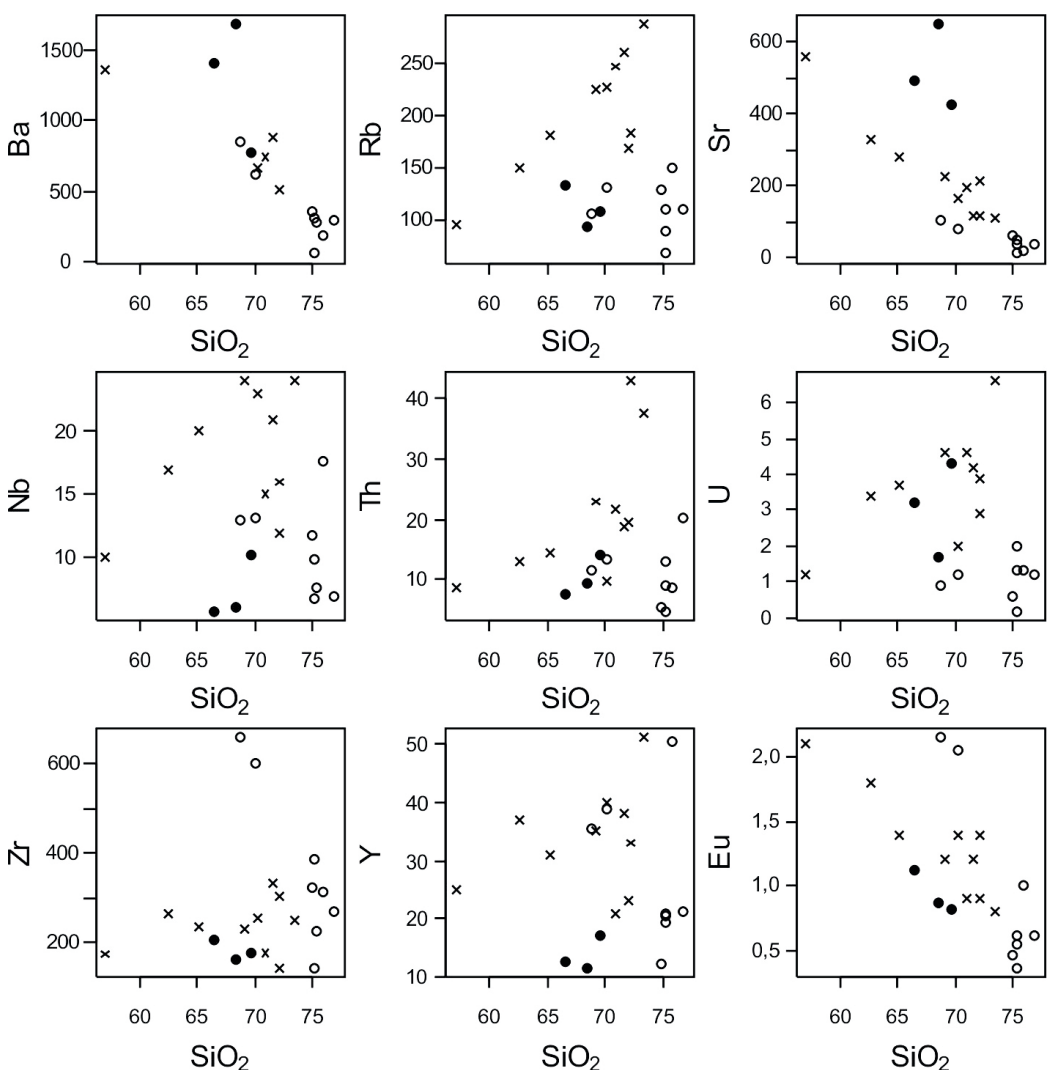

Figura 6. Diagramas binários de elementos-traço (simbologia como da Figura 5). 
et al. (1987) indica afinidade com granitos tipo-A2 para o Granito Aragão e para a SIC (Figura 9D).

Nos diagramas de ambiência tectônica de Pearce et al. (1984), as amostras do Granito Aragão e da SIC ocupam a porção limítrofe entre os campos de granitos de arco vulcânico e intraplaca no diagrama e a área coincidente com granitos pós-orogênicos, de acordo com Pearce (1996).
As amostras dos granitoides isotrópicos do Complexo Cuiú-Cuiú ocupam preferencialmente o campo de granitos de arco vulcânico e, subordinadamente, a área coincidente com granitos pós-orogênicos (Figura 10A). No diagrama de Schandl e Gorton (2002), as amostras das três unidades ocupam preferencialmente o campo das rochas relacionadas a margens continentais ativas (Figura 10B).
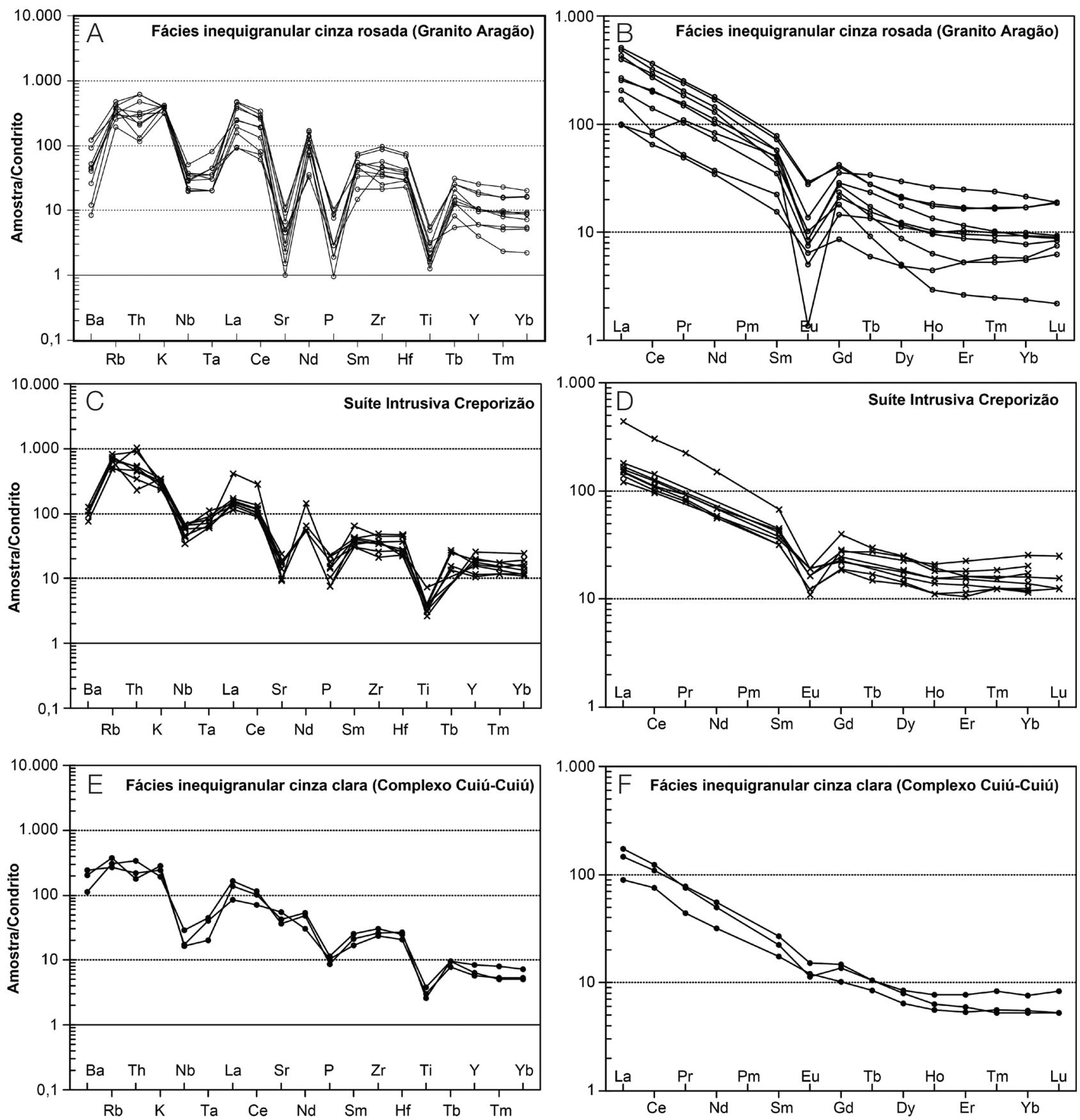

Figura 7. Diagramas multielementos normalizados pelos condritos de Thompson (1982) (A, C, E) e de Boynton (1984) (B, D, F). 

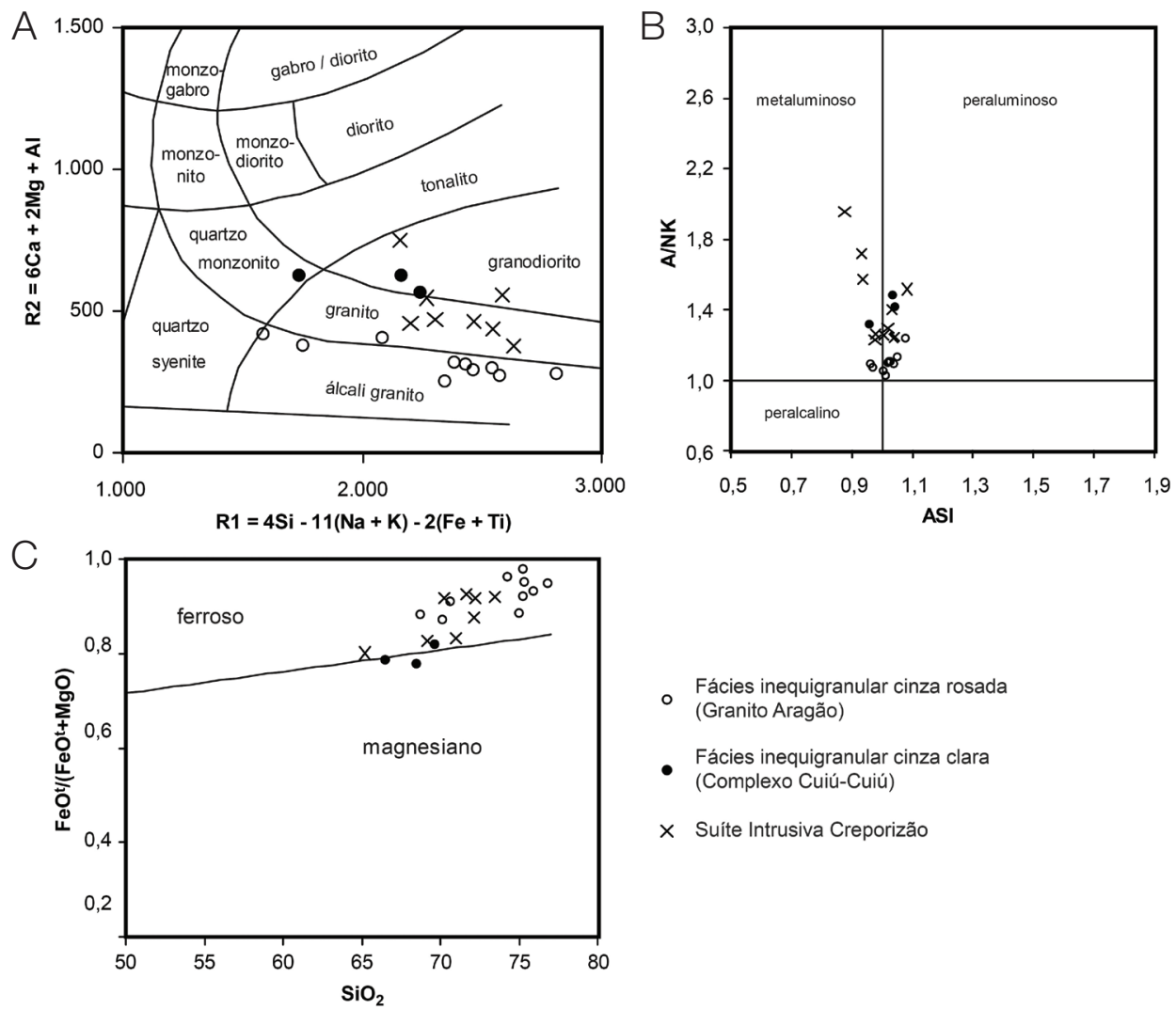

- Fácies inequigranular cinza rosada (Granito Aragão)

Fácies inequigranular cinza clara

(Complexo Cuiú-Cuiú)

$\times$ Suíte Intrusiva Creporizão

Figura 8. (A) Parte do diagrama R1 versus R2 de De La Roche et al. (1980); (B) diagrama ANK versus ASI (índice de saturação de alumínio) de Frost et al. (2001); (C) diagrama FeOt/(FeOt + MgO) de Frost et al. (2001).
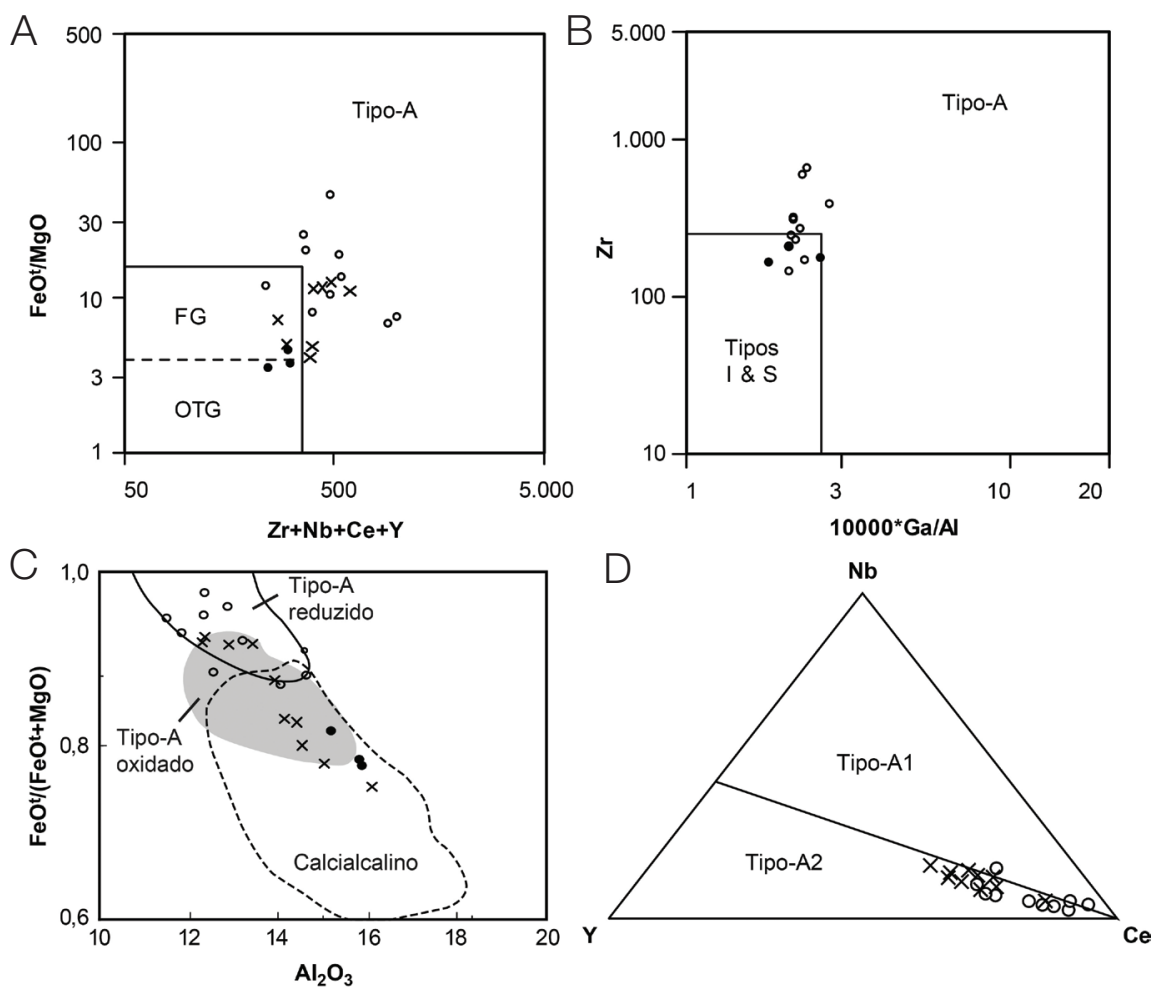

Figura 9. Diagramas de classificação de granitos: (A, B) diagramas de Whalen et al. (1987); (C) diagrama de Dall'Agnol e Oliveira (2007); (D) diagrama de Eby (1992). 

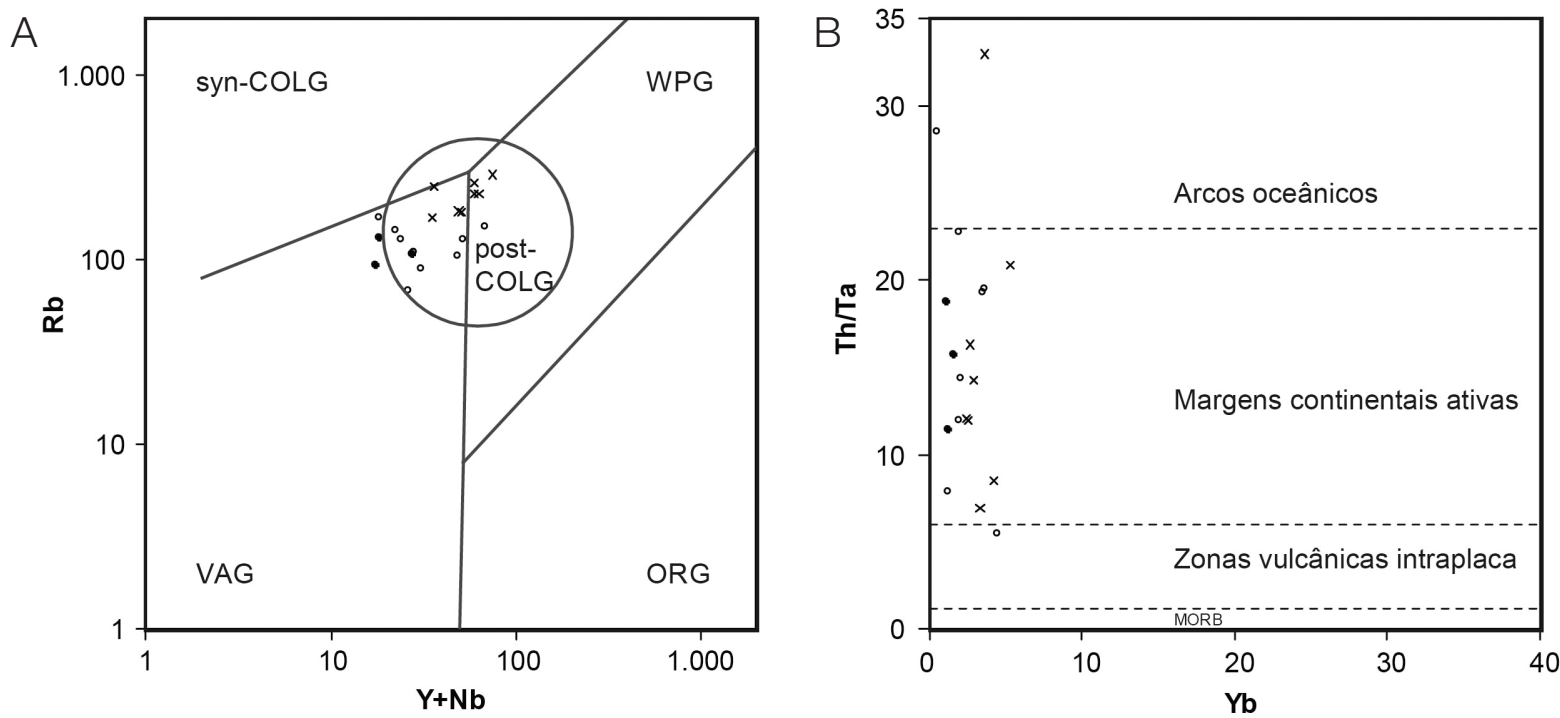

Figura 10. Diagramas de ambiência tectônica para os granitoides estudados: (A) diagrama de Pearce et al. (1984); (B) diagrama de Schandl e Gorton (2002).

\section{CONCLUSÕES}

Os dados de campo e petrográficos indicam uma expressiva similaridade entre as fácies dos granitoides espacialmente associadas ao Granito Aragão, de acordo com o que fora definido inicialmente. Diferem essencialmente pelo conteúdo de minerais máficos. Este trabalho demonstra também a ocorrência de granitoides sin-orogênicos (fácies equigranular média foliada) como encaixantes dos corpos graníticos isotrópicos. Os dados geocronológicos apontam para uma idade de cristalização de $2009 \pm 4$ Ma para os granitoides sin-orogênicos, permitindo correlacioná-los aos granitoides foliados, relacionados do Complexo Cuiú-Cuiú, no Pará. As idades de cristalização da fácies inequigranular cinza rosada (1964 $\pm 11 \mathrm{Ma}$ e $1967 \pm 2 \mathrm{Ma})$ indicam que ela pode ser incluída na SINH e é representativa do Granito Aragão. A idade de cristalização de $1995 \pm 5$ Ma obtida para a fácies inequigranular cinza-clara é compatível com as idades obtidas para granitoides do Complexo Cuiú-Cuiú e da SIC na Província Mineral do Tapajós, permitindo sua correlação. Dessa forma, observa-se que o Granito Aragão ocupa uma área de $\sim 80 \mathrm{~km}^{2}$, o que permite defini-lo como um stock granítico. O megaenclave de idade igual a 1,95 $\mathrm{Ga}$, que representa a fácies cinza clara antes considerada parte do Granito Aragão é aqui interpretado como restitutos do complexo Cuiú-Cuiú reabsorvido pelo magma gerador do Granito Aragão.

Os padrões de distribuição de elementos maiores e de elementos-traço das fácies inequigranulares cinza rosada (Granito Aragão) e cinza-clara (Complexo Cuiú-Cuiú) indicam significativas diferenças entre as mesmas. As amostras do Granito Aragão possuem um padrão geoquímico enriquecido em $\mathrm{K}_{2} \mathrm{O}, \mathrm{FeO}^{\mathrm{t}}, \mathrm{Zr}$ e elementos terras raras pesados e empobrecido em Ba, Sr e Eu, típico de magmas com afinidade tipo-A2. Os granitoides isotrópicos do Complexo Cuiú-Cuiú possuem padrões enriquecido em $\mathrm{Ba}, \mathrm{Sr}$ e Eu e empobrecido em elementos terras raras pesados, similares aos observados em magmas shoshoníticos. Ambas as fácies mostram relação com magmas de margens continentais ativas, porém os granitoides isotrópicos do Complexo CuiúCuiú apresentam padrões de magmas graníticos menos evoluídos, quando comparados aos padrões do Granito Aragão.

A inclusão do Granito Aragão na SINH e sua correlação com os granitoides da SIC, bem como de suas rochas encaixantes com o Complexo Cuiú-Cuiú, mostram que a porção leste da PAAF pode representar a extensão da Província Tapajós-Parima, ao sul do Gráben do Cachimbo.

\section{AGRADECIMENTOS}

Os autores agradecem aos projetos de pesquisa do Programa Nacional de Cooperação Acadêmica (PROCAD UFMTUNICAMP) e do Instituto Nacional de Ciência e Tecnologia de Geociências da Amazônia (INCT/GEOCIAM) pelo suporte financeiro; e ao Programa de Pós-Graduação em Geociências da UFMT, aos professores e aos colegas que auxiliaram no desenvolvimento deste trabalho. A primeira autora agradece à Coordenação de Aperfeiçoamento de Pessoal de Nível Superior (CAPES) pela concessão da bolsa de mestrado. 


\section{REFERÊNCIAS}

Arculus, R. J. (2003) Use and Abuse of the Terms Calcalkaline and Calcalkalic. Journal of Petrology, 44(5).

Assis, R. R. (2011). Depósitos auríferos associados ao magmatismo granítico do setor leste da Província de Alta Floresta (MT), Craton Amazônico: tipologia das mineralizações, modelos genéticos e implicações prospectivas. Dissertação (Mestrado). Campinas: Instituto de Geociências-UNICAMP.

Assis, R. R. (2015). Depósitos auríferos associados ao magmatismo félsico da Província de Alta Floresta (MT), Cráton Amazônico: litogeoquímica, idade das mineralizações e fonte dos fluidos. Tese (Doutorado). Campinas: Instituto de Geociências - UNICAMP.

Assis, R. R., Xavier, R. P., Paes de Barros, A. J., Barbuena, D., Trevisan, V. G., Ramos, G. S., Teixeira, R. V., Miguel-Jr., E., Rodrigues, R. M., Stabile-Jr., A., Santos, T. J. S., Miranda, G. M. T., Barros, M. A. S. A., Pinho, F. (2014). Depósitos de $\mathrm{Au}$ e $\mathrm{Au}+$ metais de base associados a sistemas graníticos paleoproterozóicos do setor leste da Província de Alta Floresta (MT), Cráton Amazônico. In: M. G. Silva, M. B. Rocha Neto, H. Jost, R. M. Kuyumjian (Rds.). Metalogenia das Províncias Tectônicas Brasileiras. Belo Horizonte, CPRM. 589p.

Barbarin, B. (1999). A review of the relationships between granitoid types, their origins and their geodynamic environments. Lithos, 46, 605-626.

Barros, M. A. S., Barros, A. J. P., Santos, J. O. S., Rocha, M. L. B. P. (2015). Extension Of The Tapajós Domains To The Alta Floresta Gold Province: Evidence From U-Pb SHRIMP Ages OfThe Nhandu Intrusive Suíte At 1962 And 1967 Ma. XIV Simpósio de Geologia da Amazônia. Marabá: SBG.

Bettencourt, J. S., Juliani, C., Xavier, R. P., Monteiro, L. V. S., Bastos Neto, C. C., Klein, E. L., Assis, R. R., Leite Jr., W. B., Moreto, C. P. N., Fernandes, C. M. D., Pereira, V. P. (2016). Metallogenetic systems associated with granitoid magmatism in the Amazonian Craton: Na overview of the presente level of understanding and exploration significance. Journal of South American Earth Sciences, 68, 22-49.

Bowden, P., Batchelor, R. A., Chappell, B. W., Didier, J., Lameyre, J. (1984). Petrological, geochemical and source criteria for the classification of granitic rocks: a discussion. Physics of the Earth and Planetary Interiors, 35, 1-11.

Boynton, W. V. (1984). Cosmochemistry of the rare earth elements; meteorite studies. In: Henderson, P. (ed.). Rare earth element geochemistry. Elsevier Science Publishing Company, 63-114.
Chappell, B. W., White, A. J. R. (1984). I- and S-type granites in the Lachlan Fold Belt, southeastern Australia. In: Xu, K., $\mathrm{Tu}, \mathrm{G}$. (eds.) Geology of granites and their metallogenic relations. Beijing: Science Press. p. 87-101.

Chappell, B. W. (2004). Towards a unified model for granite genesis. Geological Society of America Special Papers, 389, 1-10.

Cobbing, J. (1996). Granites-an overview. EpisodesNewsmagazine of the International Union of Geological Sciences, 19(4), 103-106.

Dall'Agnol, R., Oliveira, D. C. (2007). Oxidized, magnetiteseries, rapakivi-type granites of Carajás, Brazil: implications for classification and petrogenesis of A-type granites. Lithos, 93(3-4), 215-233.

Deitos, B. K., Zan, W. G., Pierosan, R., Paes de Barros, A. J., Geraldes, M. C. (2016). Mapeamento, petrografia e geocronologia $\mathrm{U}-\mathrm{Pb}$ da região limítrofe entre os arcos magmáticos Cuiú-Cuiú e Juruena - Nova Guarita, Mato Grosso. XLVIII Congresso Brasileiro de Geologia. São Paulo: Sociedade Brasileira de Geologia, 2016. CD-ROM. De La Roche, H., Leterrier, J., Grandclaud, P., Marchal, M. (1980). A classification of volcanic and plutonic rocks using R1-R2 diagrams and major elements analysis - its relationships with current nomenclature. Chemical Geology, 29, 183-210.

Eby, G. N. (1992). Chemical subdivision of the A-type granitoids: Petrogenetic and tectonic implications. Geology, 20, 641-644.

Frost, B. R., Barnes, C. G., Collins, W. J., Arculus, R. J., Ellis, D. J., Frost, C. D. (2001). A geochemical classification for granitic rocks. Journal of Petrology, 42(11), 2033-2048.

Lameyre, J., Bowden, P. (1982). Plutonic rock type series: discriminations of various granitoid series and related rocks. Journal of Volcanology and Geothermal Research, 14, 169-186.

Leite, J. A. D., Saes, G. S. (2003). Geocronologia Pb/Pb de zircões detríticos e análise estratigráfica das coberturas sedimentares Proterozóicas do sudoeste do Cráton Amazônico. Geologia USP Série Científica, 3, 113-127.

Ludwig, K. R. (2001). SQUID 1.02, A User's Manual. Berkeley Geochronology Center Special Publication, 2.

Miguel Júnior, M. (2011). Mineralizações auríferas do lineamento Peru-Trairão Província Aurífera de Alta Floresta-MT: controle estrutural e idade U-Pb das rochas hospedeiras. Dissertação (Mestrado). Campinas: Instituto de Geociências - UNICAMP. 
Moreton, L. C., Martins, E. G. (2005). Geologia e Recursos Minerais de Alta Floresta. Vila Guarita. Escala 1:250.000. Brasília: Serviço Geológico do Brasil, CPRM. 68p.

Morrison, G. W. (1980). Characteristics and tectonic setting of the shoshonite rock association. Lithos, 13, 97-108.

Moura, M. A. (1998). O maçiço granítico Matupá no depósito de ouro Serrinha (MT): petrologia, alteração hidrotermal e metalogenia. Tese (Doutorado). Brasília: Instituto de Geociências - UnB.

Nardi, L. V. S. (2016). Granitoides e Séries Magmáticas: o estudo contextualizado dos granitoides. Pesquisas em Geociências, 43, 85-99.

Paes de Barros, A. J. P. (2007). Granitos da região de Peixoto de Azevedo - Novo Mundo e mineralizações auríferas relacionadas - Província Aurifera Alta Floresta (MT). Tese (Doutorado). Campinas: Instituto de Geociências-UNICAMP.

Peacock, M. A. (1931). Classification of igneous rock series. Journal of Geology, 39, 54-67.

Pearce, J. A., Harris, N. B. W., Tindle A. G. (1984). Trace elements discrimination diagrams for the tectonics interpretation of granitic rocks. Journal of Petrology, 25(4), 956-983.

Pearce, J. (1996). Sources and settings of granitic rocks. Episodes, 19(4), 120-125.

Rocha, M. L. B. P., Chemale, F., Barros, M. A. S., Santos J. O. S. (2015). Estudos geocrnológicos aplicados às rochas graníticas da região do Trairão - oeste da Província Aurífera Alta Floresta - Cráton Amazônico/MT. XIV Simpósio de Geologia do Centro-Oeste. Brasília: SBG. CD-ROM, p. 27-29.

Santos, J. O. S., Hartmann, L. A., Gaudette, H. E., Groves, D. I., Mcnaughton, N. J., Fletcher, I. R. A. (2000). New Understanding of the Provinces of the Amazon Cráton based on Integration of Field Mapping and U-Pb and $\mathrm{Sm}-\mathrm{Nd}$ Geochronology. Gondwana Research, 3(4), 453-488.

Santos, J. O. S. (2006). A compartimentação do Cráton Amazonas em províncias: avanços ocorridos no período 2000-2006. IX Simpósio de Geologia da Amazônia, CD-ROM(1). Belém: SBG.

Santos, J. O. S., Van Breemen, O. B., Groves, D. I., Hartmann, L. A., Almeida, M. E., McNaughton, N. J., Fletcher, I. R. (2004). Timing and evolution of multiple Paleoproterozoic magmatic arcs in the Tapajós Domain, Amazon Craton: constraints from SHRIMP and TIMS zircon, baddeleyite and titanite U-Pb geochronology. Precambrian Research, 131, 73-109.
Santos, J. O. S., Barros, M. A. S., Paes de Barros, A. J., McNaughton, N. (2015). Datação de titanita usando a relação 208Pb/232Th: caso do Gnaisse Gavião, Província Aurífera Alta Floresta. XIV Simpósio de Geologia da Amazônia, CD-ROM. Pará: SBG-NO.

Schandl, E. S., Gorton, M. P. (2002). Application of high field strength elementes to discriminate tectonic setting in VMS environments. Economic Geology, 97, 629-642.

Shand, S. J. (1943). Eruptive Rocks: Their Genesis, Composition, Classification, and Their Relation to OreDeposits with a Chapter on Meteorite. New York: John Wiley \& Sons. 444 p.

Sheth, H. C., Torres-Alvarado, I. S., Verma, S. P. (2002). What is the "calc-alkaline rock series"? International Geology Review, 44(8), 686-701.

Silva, M. G., Abram, M. B. (2008). Projeto Metalogenia da Província Aurífera Juruena - Teles Pires, Mato Grosso. Goiânia, Serviço Geológico Brasileiro, CPRM, 212 p.

Souza, J. P., Frasca, A. A. S., Oliveira, C. C. (2005). Geologia e Recursos Minerais da Província Mineral de Alta Floresta. Relatório Integrado. Brasília: Serviço Geológico Brasileiro, CPRM. 164 p.

Tassinari, C. C. G., Macambira, M. J. B. (1999). Geological provinces of the Amazonian Craton. Episodes, 22, 173-182.

Thompson, R. N. (1982). Magmatism of British Tertiary volcanic province. Scottish Journal of Geology, 18, 49-107.

Vasquez, M. L., Ricci, P. S. F., Klein, E. L. (2002). Granitoides Pós-colisionais da Porção Leste da Província Tapajós. In: E. L. Klein, M. L. Vasquez, L. T. Rosa-Costa (org.). Contribuições à Geologia da Amazônia (3, 67-84). Belém: Sociedade Brasileira de Geologia - Núcleo Norte.

Vitório, J.A. (2010). A Suite Granítica Teles Pires da Província Aurifera Alta Floresta: Caracteristicas Petrográficas, Geoquímicas e Implicações Metalogenéticas. Iniciação Científica. Campinas: Instituto de Geociências - UNICAMP. 21p.

Whalen, J. B., Currie, K. L., Chappell, B. W. (1987). A-type granites: geochemical characteristics, discrimination and petrogenesis. Contributions to Mineralogy and Petrology, 95, 407-419.

Williams, I. S. (1998). U-Th-Pb geochronology by ion microprobe. In: M. A. McKibben, W. C. Shanks, W. I. Ridley (Eds.), Applications of Microanalytical Techniques to Understanding Mineralizing Processes (7, 1-35). Reviews in Economic Geology. 